\title{
ENTRE A JUSTIÇA E A SOLIDARIEDADE: A CIDADANIA QUE SE EXERCE NA POLÍCIA CIVIL BRASILEIRA
}

\author{
Ludmila Ribeiro
}

Julita Lemgruber

Klarissa Almeida Silva

\section{RESUMO}

Pretende-se discutir o papel da Polícia Civil em um cenário democrático, quando a cidadania deveria encontrar-se plenamente institucionalizada. Para tanto, serão utilizadas informações (quantitativas e qualitativas) referentes a 235 delegacias brasileiras, coletadas no âmbito da III Semana de Visitas a Delegacias de Polícia (2009), uma pesquisa internacional que tem como objetivo levar cidadãos, potenciais usuários dos serviços oferecidos por tais agências, a avaliar o atendimento ao público e a transparência dos serviços prestados pelas delegacias de polícia. O objetivo é relacionar as definições teóricas de solidariedade e justiça a determinadas percepções de cidadania que podem ser inferidas das avaliações realizadas. Para tanto, o presente artigo está estruturado em três seções, além da introdução e da conclusão. A primeira apresenta a "Semana de Visitas a Delegacias de Polícia" em suas distintas dimensões. A segunda contextualiza os conceitos a partir dos quais se pretende analisar a atuação da Polícia Civil brasileira, quais sejam: cidadania civil e seu deficit. A terceira reproduz as representações dos indivíduos acerca das práticas observadas nas delegacias de polícia e problematiza em que medida estas coadunam-se ou não com a categoria conceitual "deficit de cidadania", construída na seção anterior. Ao final, são apresentados alguns apontamentos sobre como a qualidade do atendimento prestado pelas delegacias de polícia pode ajudar no entendimento da dificuldade de se compatibilizar, no Brasil, os ideais de justiça e solidariedade, desde uma perspectiva universal. Os resultados indicam que o atendimento oferecido por essas agências policiais é inadequado e, conseqüentemente, incapaz de coadunar-se com os "princípios de justiça e solidariedade" que estruturam a própria idéia de cidadania.

PALAVRAS-CHAVE: cidadania; justiça; solidariedade; Polícia Civil; qualidade do serviço policial.

\section{INTRODUÇÃO ${ }^{1}$}

A proposta deste artigo é problematizar o papel da Polícia Civil em um cenário democrático, quando a cidadania deveria encontrar-se plenamente institucionalizada. O ponto de partida é o processo de reforma das organizações policiais, que tem sido empreendido em toda a América Latina com o final dos regimes ditatoriais nos anos 1980 e 1990.

Os estudos já realizados têm constatado que, em boa medida, todos os países latino-americanos

\footnotetext{
1 Uma primeira versão deste artigo foi apresentada ao $34^{\circ}$ Congresso Anual da Associação Nacional de Pós-Graduação e Pesquisa em Ciências Sociais. Agradecemos aos debatedores do trabalho, bem como aos pareceristas anônimos da Revista de Sociologia e Politica, os comentários valiosos que levaram à versão que se apresenta nesse periódico.
}

caminharam no sentido formal da criação de procedimentos e ações policiais mais compatíveis com a idéia de cidadania civil ${ }^{2}$. Contudo, do ponto de vista material, poucos têm sido os avanços apresentados pelas organizações policiais (FRÜHLING, 2009, p. 465)

De acordo com Chevigny (2002, p. 59), isso ocorre porque essas reformas não partem de uma discussão acerca de qual deveria ser, idealmente, o papel da polícia. As causas desse problema são

\footnotetext{
2 Conforme destacado por Marshall (1967), o conceito de cidadania civil remete à idéia de integridade física, igualdade perante a lei, direito à justiça e liberdade de pensamento. Suas principais instituições estatais são a polícia e o poder Judiciário, as quais devem ser entendidas como organizações suficientemente imparciais e confiáveis para a garantia de tais direitos. Esse conceito será melhor explicitado na seção IV deste artigo.
}

Rev. Sociol. Polít, Curitiba, v. 20, n. 42, p. 141-166, jun. 2012 
relacionadas ao fato de que os estudos sobre o tema são relativamente recentes. Além disso, existe uma grande dificuldade em definir o papel dessa organização na sociedade.

Em relação ao primeiro problema, Barreira e Adorno (2010, p. 305) destacam que, até a década de 1990, o crime e, conseqüentemente, as instituições responsáveis por sua administração não tinham para as Ciências Sociais estatuto de objeto relevante se comparado, em termos de importância, aos temas e questões relacionados ao mercado, ao mundo do trabalho, à indústria e ao empresariado, ao lado de outros mais afinados com processos de reprodução social nas instituições sociais (como família e escola), à dominação ou à participação e à representação políticas (como o estudo dos partidos e das instituições dos poderes Executivo e Legislativo). Logo, nessa época, os poucos estudos existentes sobre o tema tratavam o crime como patologia social e as polícias como forças de repressão das classes marginalizadas.

Quanto ao segundo problema, a dificuldade em definir-se o papel da polícia resulta da própria palavra "policiamento", que implica um duplo significado: um relacionado à proteção das pessoas - por meio da manutenção da ordem (o que pode ocorrer pela via do patrulhamento ou pela detenção de suspeitos) e outro relacionado à investigação dos delitos praticados que são reportados à polícia judiciária. No caso brasileiro, essa controvérsia é em parte mitigada pela existência, no âmbito estadual $^{3}$, de duas polícias: a Militar e a Civil.

Do ponto de vista legal, como estabelecido no $\S 4^{\circ}$ do artigo 144 da Constituição Federal, a Polícia Civil, vinculada aos poderes executivos estaduais, tem a competência de apurar as infrações penais, excetuadas as militares, e executar as funções de polícia judiciária, ou seja, realizar as investigações criminais. A Polícia Militar também é subordinada ao chefe do governo estadual e tem a responsabilidade de realizar o policiamento ostensivo e preservar a ordem pública $\left(\S 5^{\circ}\right.$, inciso IV do art. 144 da Constituição Federal).

\footnotetext{
3 Já que, para o âmbito federal, nos termos do art. 144 da Constituição Federal, existem as seguintes polícias: Polícia Federal, Polícia Rodoviária Federal e Polícia Ferroviária Federal.
}

Logo, para que a Polícia Civil possa atuar é necessário que a ocorrência de um delito chegue ao seu conhecimento, o que pode implicar a ida de um policial militar à delegacia para o registro da ocorrência ou no comparecimento de um cidadão à delegacia de polícia para registrar um crime ou ser testemunha de algum delito praticado. Apenas a partir desses eventos, denominados por Misse (1999) de "criminação" - ou adequação da letra da lei a uma conduta humana, é que a fase de coleta de provas para incriminação de um indivíduo como responsável pela prática de um delito pode acontecer. Com essa divisão de tarefas, torna-se evidente que, no caso brasileiro, raras são as situações nas quais a Polícia Civil é chamada à atividade de patrulhamento ${ }^{4}$.

Por outro lado, é importante destacar que, ademais da definição da "missão constitucional" de cada polícia, muito pouco se discute acerca dos modus operandi recomendáveis para essa instituição. Em parte, o aumento das taxas de criminalidade, vivenciadas pelo Brasil ao longo dos anos 1980 e 1990 (Gráfico 1), fez que o debate acadêmico deixasse de discutir o que a polícia poderia fazer para analisar o que efetivamente se fazia para reduzir os delitos (CANO, 2006). Afinal, a visão política predominante nessas décadas era a de que o trabalho da polícia consistia em reduzir o crime a partir do combate direto ou, para utilizar a metáfora muitas vezes empregada pelos políticos, da "guerra contra o crime".

\footnotetext{
4 As exceções seriam, por exemplo, as incursões que a Polícia Civil faz em conjunto com a Polícia Militar nas favelas do Rio de Janeiro. Um exemplo de intervenção nesse sentido pode ser conferida em PM FAZ OPERAÇÃO (2010).
} 

2000)

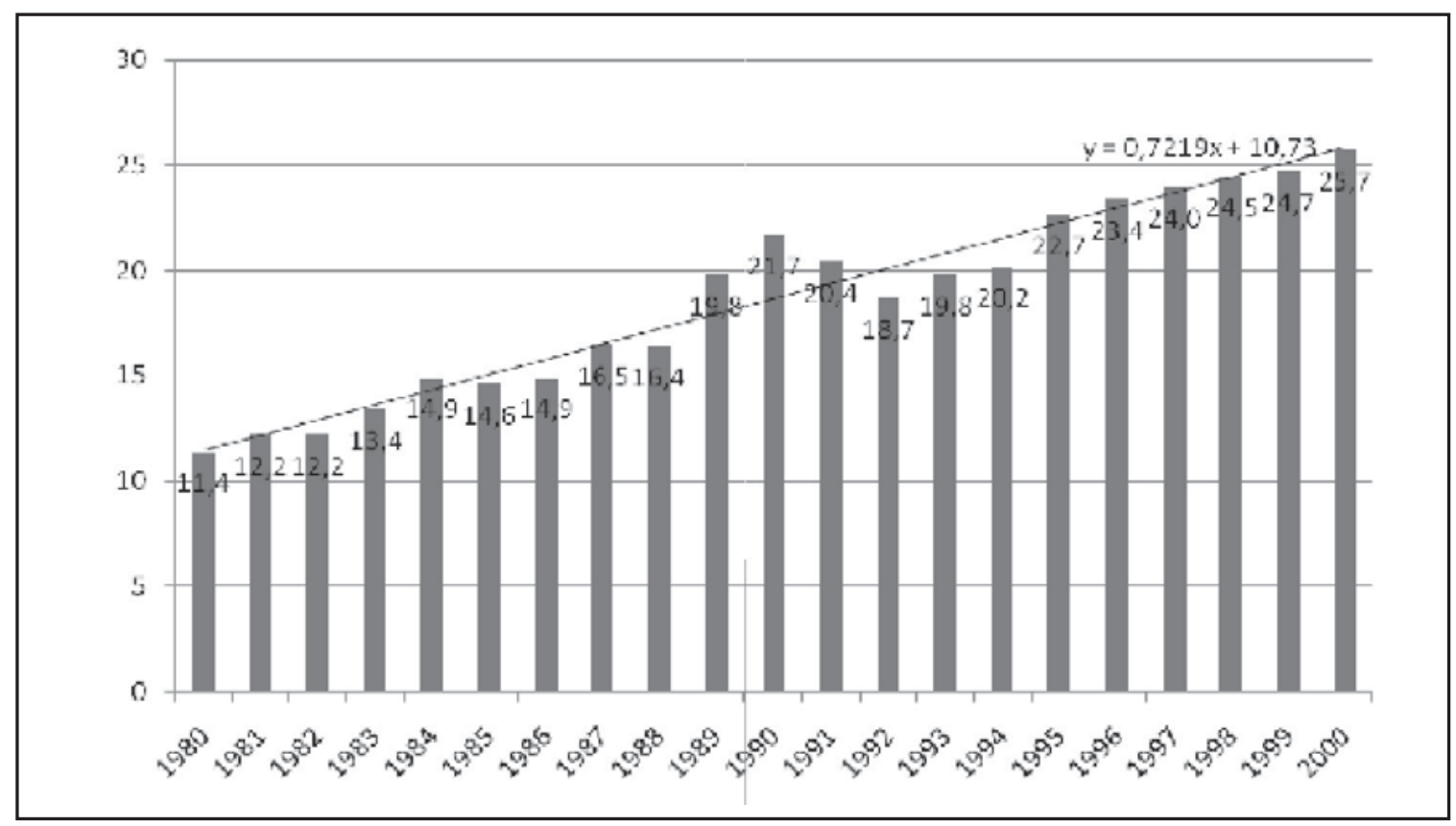

FONTE: Senasp (2003).

A visão política da polícia, por sua vez, ensejou uma grande quantidade de trabalhos acadêmicos que tinha como objetivo, se não problematizar, pelo menos descrever os problemas do cotidiano operacional da polícia 5 . De maneira geral, revisando os principais estudos sobre a forma como a organização policial funciona, é possível classificá-los em quatro categorias distintas ${ }^{6}$.

Em primeiro lugar, situam-se os estudos que abordam as práticas dos policiais civis quando do recebimento de demandas variadas, jurídicas ou não. Como bem destaca Poncioni, "o trabalho diário do policial é 'invadido' por pequenos e

\footnotetext{
5 De acordo com Lima (2009, p. 2), em abril de 2007, o banco de teses e dissertações do portal Capes possuía 2 044 trabalhos contendo "violência" como palavra-chave; 2 699 para "direitos humanos"; 1075 pesquisas para "criminalidade"; 790 para "polícia"; 621 para "justiça criminal"; 174 para "prisões", 124 para "tráfico de drogas" e, finalmente, 18 para "guardas municipais". Esses dados apenas evidenciam o maior interesse da comunidade acadêmica pelo tema em geral e pelas organizações policiais em especial.

6 Para uma análise minuciosa de como as delegacias de polícia funcionam e de como esses quatro tipos de estudos podem se combinar em um único, ver Kant de Lima (1995).
}

grandes dramas da população, em especial do seu segmento pobre, o que obriga a polícia a intervir em situações absolutamente descoladas do que se constitui um problema legal e/ou penal" (PONCIONI, 2006, p. 172). É exatamente esse tipo de situação, denominada pela própria polícia carioca de "feijoada" desenvolvimento de um enorme poder discricionário do policial na administração dos conflitos interpessoais.

Em segundo lugar, as análises que enfocam o modelo de investigação utilizado pela polícia acabam por ser um problema em vez de uma solução para a eficiência das investigações. Assim decorre por enfatizarem a discussão de que o inquérito policial, por sua característica excessivamente formal, é recheado de análises jurídicas que deveriam ser de responsabilidade do Ministério Público.

\footnotetext{
7 De acordo com Poncioni (2006), a "feijoada" é composta por casos diversos que chegam às delegacias de polícia nos quais, a partir da interação com o público, o policial desenvolve um processo de negociação da lei e da realidade que lhe permite manter a ordem, ainda que não necessariamente em acordo com a lei.
} 
A conseqüência perversa desse modelo é o atraso das investigações, já que cada passo da atividade policial deve ser minuciosamente documentado, obedecendo a princípios "cartoriais", absolutamente desnecessários à boa investigação (MISSE et alii, 2010). Um dos resultados desse conjunto de problemas é a baixíssima taxa de esclarecimento de crimes pela Polícia Civil. Mesmo crimes graves, como o homicídio doloso, apresentam taxas de esclarecimento vergonhosamente baixas. $\mathrm{Na}$ cidade do Rio de Janeiro, por exemplo, a taxa de esclarecimento deste crime situa-se na faixa de $8,1 \%^{8}$.

Os trabalhos que focam as externalidades produzidas pelas disfunções da ação policial podem ser mencionados como componentes de um terceiro grupo de pesquisa. Esses estudos que têm como objetivo compreender como uma interação inadequada (do ponto de vista legal) com a polícia ou com os organismos de controle da atividade policial (como ouvidorias e corregedorias) faz que esse indivíduo não mais procure o órgão para comunicar a vitimização por crime ou o testemunho de um delito. Como decorrências desse fenômeno, têm-se o aumento da subnotificação e da própria impunidade dos casos de violência policial, já que os civis desacreditam que os policiais possam agir de acordo com a lei e, caso não o façam, que possam ser punidos por seus superiores (LEMGRUBER, CANO \& MUSUMESCI, 2003).

Por fim, têm-se os estudos estatísticos que buscam desmistificar a relação entre a forma de atuação das polícias e as taxas de criminalidade. Essas análises demonstram que ações policiais marcadas pelo desrespeito aos direitos humanos não parecem ser a resposta para o problema da violência urbana, posto que os locais com maiores incidências criminais são também os locais que sofrem a ação mais repressiva da polícia (PERES et alii, 2008).

Logo, apesar de a cidadania civil ser o elemento que, por definição, torna as pessoas iguais perante a lei, independentemente de seu status, o que os estudos já realizados sobre o tema parecem denotar é a usual incapacidade da Polícia Civil em fazer valer a igualdade de direitos de todos os

8 Como denota a revisão das pesquisas que mensuraram a taxa de esclarecimento, realizada por Ribeiro e Silva (2010). cidadãos. E, pior, muitas vezes ela contribui para consolidar as diferenças, ao colaborar para que a justiça acabe por penalizar indivíduos em função de seu perfil (LIMA, 2004).

Em termos teóricos, essa discussão pode enquadrar-se naquilo que Luis Roberto Cardoso de Oliveira (2005) rotulou como "déficit de cidadania", ou seja, o desequilíbrio entre as idéias de justiça e solidariedade. Então, uma Polícia Civil efetivamente democrática deveria ser capaz de dar vida a esses dois conceitos sempre que um cidadão a procura para registrar um delito ou servir de testemunha de um crime. No entanto, o que freqüentemente se observa, nos referidos estudos, é que essa instituição parece dar vida ao antônimo desses termos.

Como a Semana de Visitas a Delegacias de Polícia é um projeto no âmbito do qual a qualidade do serviço prestado pela Polícia Civil é captada pelos potenciais usuários do serviço, o objetivo deste artigo é relacionar as definições teóricas de solidariedade e justiça a determinadas percepções de cidadania que podem ser inferidas das avaliações realizadas. Com isso, pretende-se discutir como, no ano de 2009, em nove capitais brasileiras, os participantes do projeto captavam esse deficit de cidadania ou esse desequilíbrio entre solidariedade e justiça.

Para tanto, o presente artigo está estruturado em três seções, além da introdução e da conclusão. A primeira apresenta a "Semana de Visitas a Delegacias de Polícia" em suas distintas dimensões. A segunda contextualiza os conceitos a partir dos quais se pretende analisar a atuação da Polícia Civil brasileira, quais sejam: cidadania civil e seu deficit. A terceira reproduz as representações dos indivíduos acerca das práticas observadas nas delegacias de polícia e problematiza em que medida estas coadunam-se ou não com a categoria conceitual "deficit de cidadania", construída na seção anterior. Ao final, são apresentados alguns apontamentos sobre como a qualidade do atendimento prestado pelas delegacias de polícia pode ajudar no entendimento da dificuldade de compatibilizar-se, no Brasil, os ideais de justiça e solidariedade desde uma perspectiva universal.

\section{A SEMANADE VISITAS ADELEGACIAS DE POLÍCIA}

A Semana de Visitas a Delegacias de Polícia é uma pesquisa global, realizada simultânea e 
anualmente em mais de 20 países com o objetivo de levar cidadãos, potenciais usuários dos serviços oferecidos por tais agências, a avaliarem o atendimento que estas prestam ao público.

A idéia da pesquisa surgiu do trabalho conjunto de seis organizações distintas, sob coordenação do Vera Institute of Justice ${ }^{9}$, objetivando a criação de indicadores para o monitoramento e avaliação do desempenho do sistema de justiça criminal ${ }^{10}$. A partir desse estudo pioneiro, começou-se a desenhar a criação de uma aliança de centros de pesquisa que, contínua e permanentemente, empreendesse investigações com foco na avaliação da qualidade do serviço prestado pelas agências do sistema de justiça criminal.

Assim nasceu a Altus ${ }^{11}$, cujo principal projeto é a "Semana de Visitas a Delegacias de Polícia", um evento global e único organizado para: $i$ ) avaliar a qualidade de serviços prestados por departamentos de polícia; ii) identificar boas práticas policiais; iii) fortalecer a prestação de contas pela polícia no que diz respeito ao público que a mesma serve e $i v$ ) promover os direitos humanos. A decisão de enfatizar o tema da polícia está relacionada com o fato desta constituir-se na primeira e decisiva instância do sistema de justiça criminal, o que torna imprescindível não apenas que a comunidade conheça-a bem, mas que seja capaz de compreender seu papel e confiar em sua atuação, procurando-a sempre que ocorrer um delito.

Esse debate entre pesquisa e ação insere-se na discussão mais ampla do conceito de "seguridad

\footnotetext{
9 Organização não-governamental sediada em Nova York, hoje coordenadora geral do projeto.

10 O projeto era o "Measuring Progress toward Safety and Justice: A Global Guide to the Design of Performance Indicators across the Justice Sector" que contou com a participação das organizações que, hoje, são membros fundadoras da Altus: Centro de Estudos de Segurança e Cidadania (Brasil); Centro de Estudos em Segurança Cidadã (Chile); Fundação Cleen (Nigéria); Instituto de Desenvolvimento e Comunicação (Índia); Fundação Indem (Rússia) e o Instituto de Justiça Vera (Estados Unidos). Para maiores informações, cf. o sítio da Altus (2012).

11 A Altus hoje é uma aliança global que atua em vários continentes e adota uma perspectiva multicultural para contribuir para a melhoria da segurança pública e do sistema de justiça criminal. Para maiores informações conferir Altus (2012).
}

ciudadana", bastante difundido na América Latina como pano de fundo para analisar-se e pensar a atuação das organizações policiais ${ }^{12}$. Dentro desse contexto, devem ser criados mecanismos capazes de promover uma relação positiva entre polícia e comunidade, contribuindo para a redução da subnotificação da criminalidade ${ }^{13}$ (DAMMERT et alii, 2010).

Assim, para que a polícia pudesse ser simultaneamente avaliada quanto à sua capacidade de efetivar a idéia de cidadania civil e aproximarse da população por ela atendida, era necessário desenvolver um instrumento capaz de viabilizar o alcance de tais objetivos. A proposta da Altus passou a ser, portanto, a construção de uma pesquisa-experimento, na qual os indivíduos fossem chamados a opinar, desde uma perspectiva científica ${ }^{14}$, sobre a qualidade do serviço prestado pelas delegacias de polícia. Também, por meio deste exercício, os cidadãos deveriam conhecer melhor suas polícias.

Para desenvolver tal instrumento, a Altus mobilizou uma equipe de pesquisadores de vários países, especialistas na área da polícia. Em seguida, esses indivíduos analisaram os dispositivos de tratados internacionais sobre como as delegacias de polícia devem funcionar no sentido de garantir que os indivíduos que as procuram tenham um tratamento igualitário para registrar crimes ou fornecer informações sobre delitos de que foram vítimas ou testemunhas. Entre os principais diplomas consultados estão os seguintes:

12 Como destacado por Barreira e Adorno (2010, p. 334), o conceito de segurança cidadã não é uma criação brasileira. Trata-se de uma elaboração teórica que vem sendo forjada desde a Guerra Fria e que tem tido especial impacto nas sociedades latino-americanas egressas de regimes autoritários ou de guerra civil. No entender de Tavares dos Santos (2004, p. 172), no caso brasileiro, a incorporação do conceito de segurança cidadã como referente para a elaboração das políticas de reforma da polícia representa uma ruptura epistemológica com o conceito de segurança pública que, nessa localidade, é sempre entendida como segurança provida pelo Estado, com o propósito de viabilizar a manutenção da lei e da ordem.

13 A subnotificação criminal é a diferença entre a quantidade de crimes que acontecem e a quantidade dos que chegam ao conhecimento da polícia.

14 Posto que os indivíduos recebem um treinamento para o preenchimento do questionário, como ocorre em qualquer pesquisa do gênero. 
i) United Nations Body of Principles for the Protection of all Persons Under any Form of Detention or Imprisonment; ii) United Nations Convention on the Elimination of All Forms of Discrimination Against Women; iii) United Nations Covenant on Civil and Political Rights (Iccpr); iv) United Nations Declaration of Basic Principles of Justice for Victims of Crime and Abuse of Power ("Victims Declaration"); v) United Nations Declaration on the Elimination of All Forms of Racial Discrimination (CERD); vi) United Nations Declaration on the Protection of All Persons from Enforced Disappearance; vii) United Nations Standard Minimum Rules for Non-Custodial Measures ("the Tokyo Rules"); viii) Universal Declaration of Human Rights ${ }^{15}$.

A partir desse material, foram formuladas 20 perguntas básicas, agrupadas em cinco blocos temáticos: $i$ ) orientação para a comunidade; ii) condições materiais; iii) igualdade de tratamento ao público; vi) transparência e prestação de contas; v) condições de detenção. Contudo, para garantir-se que as opiniões e impressões dos visitantes pudessem ser registradas de maneira simultaneamente iguais e diferenciadas, além das 20 questões a serem respondidas de acordo com a escala Likert (cinco pontos, variando desde totalmente inadequada até excelente), esse formulário continha ainda uma seção em que o indivíduo poderia registrar suas impressões mais livremente.

Finalizado o processo de confecção do instrumento, foi realizado um pré-teste em oito países. Os resultados obtidos demonstraram que a ferramenta era, de fato, capaz de alcançar os objetivos propostos - de avaliação da qualidade do serviço prestado pelas delegacias de polícia e de aproximação entre essa agência e a comunidade por ela servida. Ao final, o questionário foi disponibilizado no sítio das organizações que participaram do projeto e no site da Altus.

No ano de 2004, o então Governador do Ceará encontrou o questionário e manifestou o desejo de utilizá-lo para avaliar as delegacias da capital de seu estado, Fortaleza. O mesmo ocorreu com

\footnotetext{
15 Os nomes foram mantidos em inglês para evitar quaisquer problemas de tradução que pudessem inviabilizar a correta identificação dos diplomas legais utilizados para a elaboração do questionário.
}

o Departamento de Segurança Pública da África do Sul. Percebendo o interesse despertado pela ferramenta, a Altus decidiu partir para uma nova etapa do projeto: transformar a utilização do questionário em um acontecimento global que congregasse, simultaneamente, instituições de pesquisa e cidadãos. Assim, surgiu a Semana de Visitas a Delegacias de Polícia, que vem sendo realizada anualmente desde o ano de 2006. Inicialmente, essa atividade acontecia sob os auspícios de um conjunto de financiadores, mas, desde 2009, a Semana de Visitas é financiada pelo Department for International Development (DFID), do governo britânico.

No Brasil, em 2009, a Semana de Visitas aconteceu em nove regiões metropolitanas: Belém, Fortaleza, Recife, Goiânia, Brasília, Rio de Janeiro, Belo Horizonte, São Paulo e Porto Alegre. Essas capitais foram escolhidas por possuírem centros de pesquisa especializados na análise das organizações policiais e capazes de replicar a metodologia do projeto, viabilizando a realização das visitas de maneira simultânea.

No que se refere à escolha das delegacias avaliadas, estas foram sorteadas aleatoriamente de acordo com os seguintes quantitativos: vinte delegacias distritais e uma Delegacia Especializada de Atendimento à Mulher (DEAM) em cada localidade. Em São Paulo e no Rio de Janeiro, em virtude do tamanho da população e do número de delegacias, foram sorteadas 40 delegacias distritais e duas DEAMs. São Paulo e Rio de Janeiro contaram com amostras duplicadas porque tais cidades concentram quase metade do total de delegacias distritais existentes em todo o país.

Uma vez estabelecido o quantitativo de delegacias a serem visitadas em cada localidade, passou-se à escolha das mesmas. O critério adotado foi o de amostragem aleatória: a partir de uma listagem das delegacias não especializadas, ou seja, distritais ou seccionais de cada capital e região metropolitana (essas são as delegacias de bairro ou aquelas que fazem atendimento ao público de maneira geral), foi gerada uma lista de números aleatórios, sendo que cada número correspondia a uma delegacia. Os 20 primeiros números foram considerados como elementos integrantes do conjunto principal de delegacias que seriam visitadas pela Altus. As demais delegacias foram descartadas (ou não inseridas na amostra). 
Por serem apenas uma as DEAMs de cada capital, elas foram automaticamente incluídas na amostra.

Quanto ao processo de coleta dos dados propriamente dito, pode-se afirmar que foram empregados os procedimentos característicos da etnometodologia. De acordo com Giddens e Turner (1999, p. 14), os partidários dessa metodologia enfatizam a importância da descrição pormenorizada de processos empíricos, aparentemente desconsiderando o que constituiria a explicação ou a cientificidade da descrição. Logo, acredita-se que os dados coletados no âmbito da Semana de Visitas a Delegacias de Polícia podem ser considerados válidos e produzidos dentro da lógica de pesquisa etnometodológica porque os visitantes (que realizam a coletada de informações) recebem treinamento específico no uso da ferramenta e são obrigados a relatar, de maneira pormenorizada, o que observaram e como observaram. Logo, para garantir-se a realização da avaliação da mesma forma em todas as localidades, o representante da Altus em cada país treina os coordenadores regionais que, por sua vez, treinam os coordenadores de visitas e os visitantes.

Durante a visita que, em média, tem duração de uma hora e meia, os indivíduos recrutados para a avaliação apenas observam, conversam e vivenciam a rotina da delegacia de polícia. Após a visita, cada qual responde ao questionário, de acordo com a escala Likert - que, como já mencionado, varia entre totalmente inadequado (valor um) e excelente (valor cinco). Em seguida, os visitantes discutem suas impressões e a partir do conhecimento construído de maneira compartilhada, o coordenador preenche a última parte do questionário, que consiste na avaliação da delegacia em uma perspectiva qualitativa. Importante destacar que mesmo após a discussão do grupo, o indivíduo não pode retornar e mudar as notas anteriormente dadas, já que a proposta é avaliar a impressão inicial dos visitantes acerca da delegacia de polícia. Logo, esse relatório qualitativo contextualiza a delegacia em termos socioeconômicos, qualifica cada um dos itens mensurados de maneira quantitativa e ainda apresenta relatos de como a visita impactou a percepção dos visitantes em relação às delegacias de polícia.

A avaliação realizada por cada indivíduo e o relatório qualitativo de cada delegacia são, ao final, inseridos em um sítio privativo da Altus. A partir dessas informações, são calculados os pontos médios de cada delegacia, os quais, por sua vez, são contrastados ou balizados com os relatórios qualitativos. Assim, considerando a média de pontos recebida por cada delegacia, é possível classificar o atendimento oferecido por essa agência à população em categorias que variam desde "totalmente inadequada" até "excelente" (Tabela 1).

TABELA 1 - INTERVALOS DE PONTUAÇÃO PARA CLASSIFICAÇÃO DA QUALIDADE DO ATENDIMENTO PRESTADO PELAS DELEGACIAS DE POLÍCIA (2009)

\begin{tabular}{|l|c|}
\hline \multicolumn{1}{|c|}{ INTERVALO DE PONTOS } & CATEGORIA \\
\hline $20-35$ pontos & Totalmente inadequado \\
$36-51$ pontos & Inadequado \\
$52-67$ pontos & Adequado \\
$68-84$ pontos & Mais do que adequado \\
$85-100$ pontos & Excelente \\
\hline
\end{tabular}

FONTE: Altus (2010, p. 19).

No ano de 2009, com o uso dessa metodologia, foi possível constatar que mais da metade das delegacias visitadas no Brasil presta um serviço que, na perspectiva do próprio usuário, é inadequado. Considerando-se tais parâmetros, $51 \%$ das delegacias brasileiras foram avaliadas como inadequadas e $18 \%$ como totalmente inadequadas. Por outro lado, $22 \%$ das delegacias visitadas foram avaliadas como adequadas e 7\% como mais do que adequadas. Apenas $2 \%$ das delegacias visitadas, de acordo com impressões dos usuários, possuem um serviço que pode ser 
classificado como excelente (Gráfico 2).

GRÁFICO 2-AVALIAÇÃO DAQUALIDADE DO ATENDIMENTO PRESTADO PELAS DELEGACIAS DE POLÍCIA

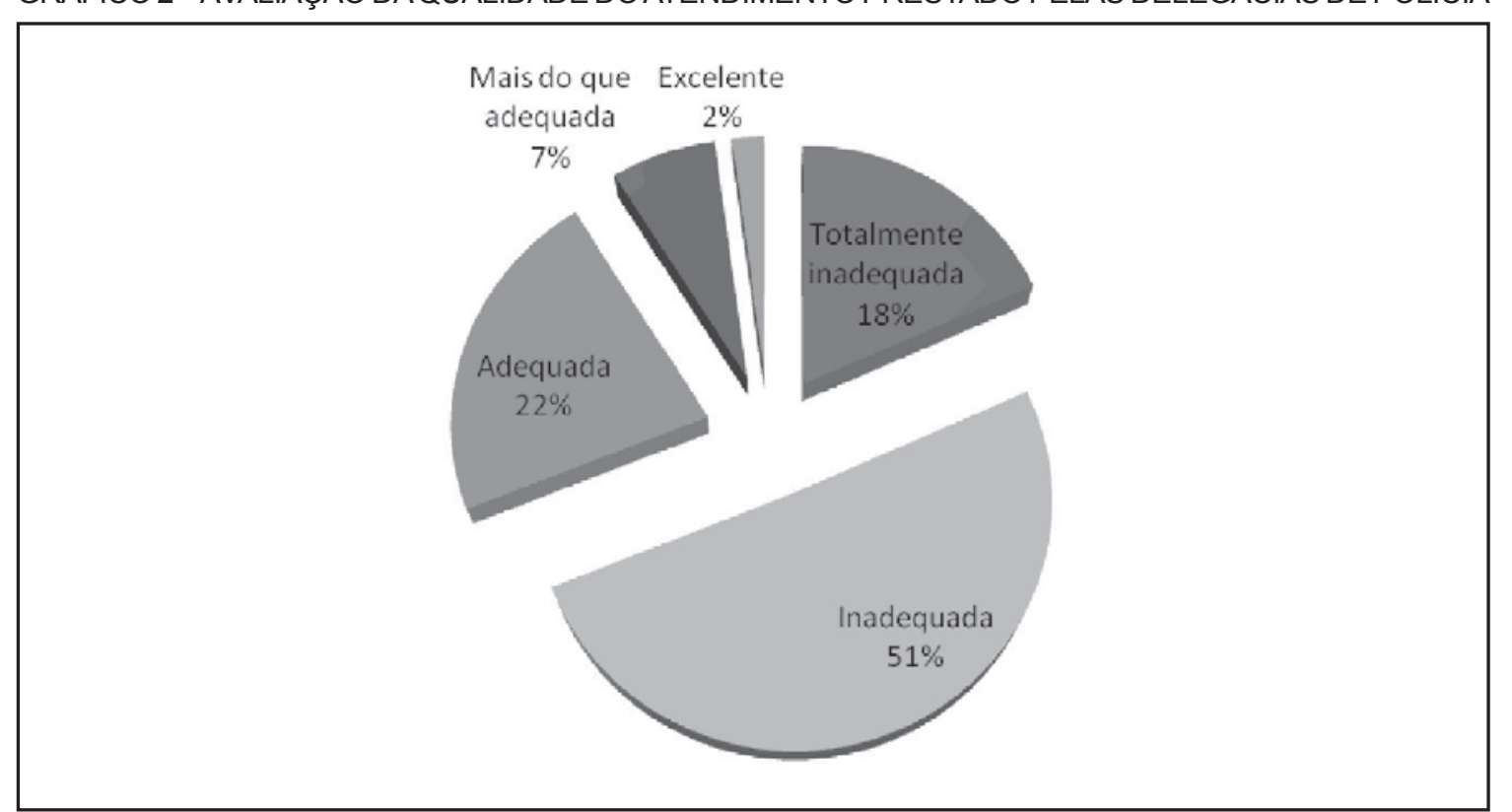

FONTE: Altus (2010, p. 20).

As delegacias de Belém do Pará, Recife, Goiânia, Fortaleza, Porto Alegre e Belo Horizonte alcançaram uma média que as classifica como inadequadas. Por outro lado, as delegacias de Rio de Janeiro,
São Paulo e Brasília alcançaram uma média que as classifica como adequadas. Logo, nenhuma delegacia brasileira foi classificada como excelente ou como totalmente inadequada (Gráfico 3).

\section{GRÁFICO 3 - MÉDIA GLOBAL DE PONTOS ALCANÇADOS PELAS DELEGACIAS DE POLÍCIA DE ACORDO} COMACIDADE

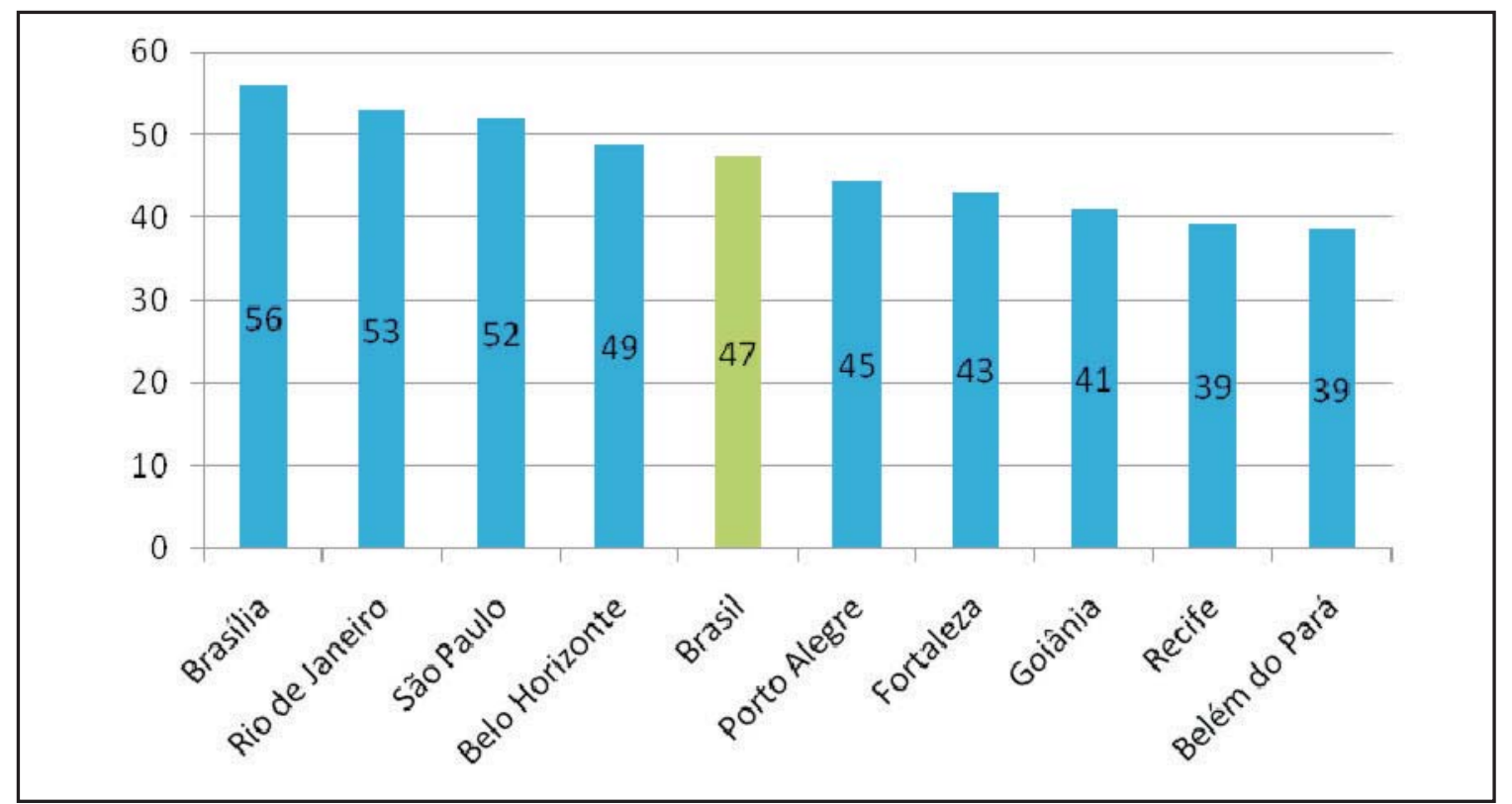

FONTE: Altus (2010, p. 22) 
No entanto, o que esses dados significam em termos da capacidade da Polícia Civil brasileira em institucionalizar o conceito de cidadania civil? Em que medida os resultados apresentados por essa pesquisa parecem indicar dilemas a serem superados? De que forma o desequilíbrio entre os conceitos de justiça e solidariedade, que estruturam a idéia de deficit de cidadania faz-se presente na Polícia Civil brasileira? Essas são algumas das questões que este artigo pretende responder. Mas, para tanto, faz-se indispensável contextualizar o debate sobre as definições de cidadania no âmbito da ciência social brasileira.

III. A QUESTÃO DA CIDADANIA E DO SEU DÉFICIT OU A DIFICULDADE EM EQUILIBRAR-SE JUSTIÇA E SOLIDARIEDADE
De acordo com Coutinho (2000), cidadania é a capacidade conquistada por alguns ou por todos os indivíduos de apropriarem-se dos bens socialmente criados, de atualizarem todas as potencialidades de realização humana abertas pela vida social em cada contexto historicamente determinado.

Na formulação de T. H. Marshall (1967), um dos primeiros a abordar a questão da cidadania do ponto de vista teórico, esse conceito possui três dimensões fundamentais, que se traduzem em três tipos de direito: os civis, os políticos e os sociais. Cada uma das três dimensões, por sua vez, institucionalizam-se na prática cotidiana dos indivíduos de um dado país por intermédio de determinadas instituições estatais, que podem ser apresentadas, de maneira esquemática, da seguinte maneira:

TABELA 2 - ELEMENTOS DA CIDADANIA, DE ACORDO COM ADEFINIÇÃO DISSEMINADA POR MARSHALL (1967) EAS INSTITUIÇÕES DEMOCRÁTICAS A ELAASSOCIADAS

\begin{tabular}{|c|c|c|}
\hline $\begin{array}{l}\text { ELEMENTOS } \\
\text { DA CIDADANIA }\end{array}$ & DEFINIÇÃO & $\begin{array}{l}\text { INSTITUIÇÕES DEMOCRÁTICAS } \\
\text { ASSOCIADAS A ESTE ELEMENTO }\end{array}$ \\
\hline Direitos Civis & $\begin{array}{c}\text { Direitos necessários para a garantia } \\
\text { da liberdade individual. Relaciona-se } \\
\text { à liberdade da pessoa; ao direito à } \\
\text { integridade física, à propriedade e à } \\
\text { justiça. }\end{array}$ & $\begin{array}{l}\text { Polícias } \\
\text { Tribunais de Justiça }\end{array}$ \\
\hline Direitos Políticos & $\begin{array}{l}\text { Direitos a participar do exercício do } \\
\text { poder político, como um indivíduo } \\
\text { investido de autoridade política ou } \\
\text { como o eleitor de tais autoridades. }\end{array}$ & $\begin{array}{l}\text { Congresso Nacional } \\
\text { Partidos políticos }\end{array}$ \\
\hline Direitos Sociais & $\begin{array}{c}\text { Direito a bem estar econômico e } \\
\text { sobrevivência material. }\end{array}$ & $\begin{array}{l}\text { Serviços sociais (educação, saúde, } \\
\text { trabalho e previdência social). }\end{array}$ \\
\hline
\end{tabular}

FONTE: os autores, a partir de De La Paz (2004).

De La Paz (2004), por sua vez, argumenta que o conceito de cidadania deve ser entendido como status legal e identidade. Assim, para cada conjunto de direitos há um conjunto de deveres. Logo, a cidadania possuiria uma dimensão muito objetiva, relacionada a direitos e deveres específicos diante do Estado, representando, portanto, uma relação em que os dois entes possuem direitos e obrigações recíprocas. Então, como argumenta Reis (1999), ser cidadão significa, de uma maneira mais geral, ser portador de direitos e obrigações e, de uma forma mais específica, compartilhar de uma identidade com os demais membros de uma comunidade política.
Desse modo, se por um lado a cidadania implica que o Estado ofereça instituições substantivamente capazes de assegurar o provimento dos direitos mencionados, por outro, a cidadania implica que os indivíduos sob seu governo sejam capazes de $i$ ) conhecer os direitos da cidadania, inclusive no que diz respeito às responsabilidades que eles implicam; $i i)$ identificar no aparelho estatal quais são as instituições responsáveis pelo provimento de cada categoria de direitos; iii) possuir instituições estatais efetivas, eficientes e confiáveis do ponto de vista de garantia dos direitos civis e $i v$ ) exercer os seus deveres e direitos de maneira legítima, de acordo com as regras da democracia. 
Portanto, a cidadania tem mais chances de ser institucionalizada quanto maior a probabilidade de os indivíduos assumirem as regras e as instituições criadas pela democracia de maneira plena. Ou seja, não basta ter instituições funcionando. É necessário ainda que os indivíduos reconheçam-se em tais instituições e a elas recorram.

De acordo com Marshall (1967), o elemento civil da cidadania compõe-se dos direitos relacionados à liberdade da pessoa, liberdade de expressão, de pensamento, de religião e de propriedade. Relaciona-se, portanto, ao direito à segurança, ao direito à justiça.

Nesse sentido, como destacado por Comparato (1981, p. 9), a segurança, como a justiça, é um valor-condição e não um valor-escopo, pois não se busca a segurança pela segurança, mas como meio de fruição e manutenção de um interesse. Assim, pode-se dizer que o direito subjetivo à segurança é uma das manifestações mais elementares da justiça. Então, todos os homens têm direito à segurança na posse ou no gozo de bens essenciais ao pleno desenvolvimento de sua personalidade. Como para que exista liberdade é necessário segurança, para que essa possa materializar-se é necessário que existam normas e agências coercitivas capazes de zelar pelo bom cumprimento dessas normas. Exatamente por isso, as instituições diretamente relacionadas com os direitos civis são as organizações policiais e os tribunais de justiça.

Logo, o direito à justiça é de natureza diferente dos restantes porque se trata do direito de defender e de fazer valer o conjunto dos direitos de uma pessoa em relação aos demais, mediante os devidos processos legais. Em um cenário ideal, os indivíduos seriam considerados como portadores de cidadania plena se, além de compreenderem o conteúdo desse direito, fossem capazes de posicionar-se de acordo com as instituições responsáveis pela administração de conflitos na ordem pública.

Alguns autores afirmam que isso não ocorre no Brasil porque existe um deficit de cidadania, termo que deve ser entendido como o desequilíbrio entre o justo e o solidário. Essa idéia é derivada da obra de Cardoso de Oliveira (1995), segundo o qual qualquer experiência de cidadania que pretenda contemplar o respeito aos direitos usualmente atribuídos ao cidadão, deverá promover um equilíbrio entre os princípios de justiça e solidariedade.

Para definição da dimensão justiça, Cardoso de Oliveira (idem) lança mão da crítica à teoria habermasiana que, de acordo com ele, é excessivamente tímida em relação à incorporação da dimensão valorativa da ética em suas propostas de equacionamento da moralidade. Apesar desse debate parecer bastante profícuo do ponto de vista teórico, para a definição desse primeiro elemento recorreu-se ao trabalho de Fraser (2009), já que este pareceu adequar-se melhor ao objetivo de constituir um arcabouço analítico que permita a compreensão do atendimento prestado pelas delegacias de polícia dentro da idéia de cidadania.

Para Fraser (idem), a justiça requer arranjos sociais que permitam a todos participarem como pares na vida social. Assim, para a superação da injustiça é necessário romper os obstáculos institucionalizados que impedem alguns sujeitos de participar, em condições de paridade com os demais, nos processos de interação social. A autora argumenta que, nesse cenário, dois são os elementos que precisam ser considerados para uma adequada compreensão do significado de justiça: i) o elemento distributivo, de acordo com o qual as pessoas não podem ser impedidas da plena participação na vida social por estruturas econômicas que lhes negam os recursos necessários para interagir com os demais na condição de pares; ii) o elemento do reconhecimento, segundo o qual as pessoas não podem ser coibidas de interagir em termos de paridade por hierarquias institucionalizadas de valoração cultural. A essas duas dimensões de justiça (distribuição e reconhecimento), é acrescentada uma dimensão política, que diz respeito à natureza da jurisdição do Estado e das regras de decisão pelas quais se estruturam as disputas sociais. Ou seja: “Ao estabelecer o critério de pertencimento social, e, portanto, determinar quem conta como um membro, a dimensão política da justiça especifica o alcance daquelas outras dimensões: ela designa quem está incluído, e quem está excluído, do círculo daqueles que são titulares de uma justa distribuição e de reconhecimento recíproco. Ao estabelecer regras de decisão, a dimensão política também estipula os procedimentos de apresentação e resolução das disputas tanto na dimensão econômica quanto na cultural: ela revela não apenas quem pode fazer reivindicações por redistribuição e 
reconhecimento, mas também como tais reivindicações devem ser introduzidas no debate e julgadas" (idem, p. 19).

Portanto, no contexto deste artigo, o conceito de justiça será entendido como elemento plenamente realizado quando um indivíduo, independentemente de sua situação econômica ou de seu status social, é capaz de realizar-se plenamente como ser político e parte integrante de determinada comunidade, sem nenhum tipo de constrangimento institucional. Logo, a escolha do conceito de justiça de Fraser (idem), em detrimento do elaborado por Cardoso de Oliveira (1995), tem como justificativa o fato de que as delegacias de polícia possuem como principais usuários pessoas de baixa renda e que, por isso, compartilham de um sentimento de injustiça perante distintas instituições estatais. Então, a dimensão justiça será compreendida desde um ponto de vista mais pragmático do que filosófico, afinal, a proposta aqui é argumentar em que medida o atendimento prestado pelas delegacias de Polícia Civil cumpre ou não o pressuposto de equilíbrio entre justiça e solidariedade.

A forma como a atividade política é recebida por parte das instituições estatais também se constitui como elemento importante para a estabilização da cidadania. Em algumas situações, o indivíduo não se vê impedido de realizar as suas atividades políticas por motivos econômicas ou de status, mas percebe-se injustiçado por não sentir que existe reciprocidade em sua relação com os entes públicos. Essa seria exatamente a dimensão da solidariedade, como apresentada no contexto do trabalho de Cardoso de Oliveira (idem).

Na construção da definição de solidariedade, o autor toma como ponto de partida a ênfase dada por Mauss ao caráter relacional do direito, expresso na noção de reciprocidade, por meio da obrigação de dar, receber e retribuir. A partir dessa definição, Cardoso de Oliveira argumenta que "a realização das trocas e/ou a institucionalização da relação entre as partes demanda, ao lado da afirmação dos direitos e deveres que condicionam a interação, o reconhecimento mútuo dos envolvidos enquanto pessoas merecedoras do tratamento especial/ individualizado reciprocado ao longo dos diferentes momentos que marcam a transação. Isto é, a ideia de que a implementação e/ou o reconhecimento dos direitos em pauta depende, em alguma medida, da consideração mútua da dignidade das partes enquanto membros legítimos de uma comunidade ou totalidade determinada, com a qual se identificam através da comunhão de valores e visões de mundo minimamente compartilhados" (idem, p. 5).

Compatibilizando essas abordagens teóricas, é possível afirmar que o desequilíbrio entre o justo e o solidário ocorre no Brasil dada a existência de um descompasso entre questões de ordem normativa e questões de ordem valorativa que terminam por fazer que determinadas regras prescritas não impliquem o reconhecimento mútuo dos envolvidos enquanto pessoas merecedoras de tratamento igualitário.

No contexto dessa análise, acredita-se que a compreensão desse desequilíbrio entre justiça e solidariedade possa ser mais bem explicitada quando a relação entre os indivíduos e as instituições policiais é tomada como foco privilegiado de estudo. Nesse sentido, considerando o trabalho de alguns autores sobre o tema, é possível afirmar que, especialmente ao longo da década de 1990, esse desequilíbrio tornouse ainda mais evidente, especialmente do ponto de vista do esgarçamento das relações de solidariedade e da própria concepção de cidadania civil ${ }^{16}$.

De acordo com Leite (2000), em razão do aumento expressivo das taxas de criminalidade (Gráfico 4), sobretudo dos crimes contra a pessoa (que são ou causam maior clamor público), o que se percebe é a disseminação de fortes reclamos por ordem e segurança como garantia dos direitos e das liberdades individuais ${ }^{17}$. Assim, pouco importa se o serviço policial oferecido à população cumpre os requisitos de justiça e solidariedade, o que interessa, em dadas circunstâncias, é que a polícia seja eficiente na atividade de contenção ao crime.

16 Talvez um indicativo desse esgarçamento seja a disseminação da seguinte expressão "direitos humanos para os honestos, cadeia para o resto" ou "direitos humanos nesse país é coisa para proteger bandido".

17 Nesse sentido, ver também Zackseski (2009). 


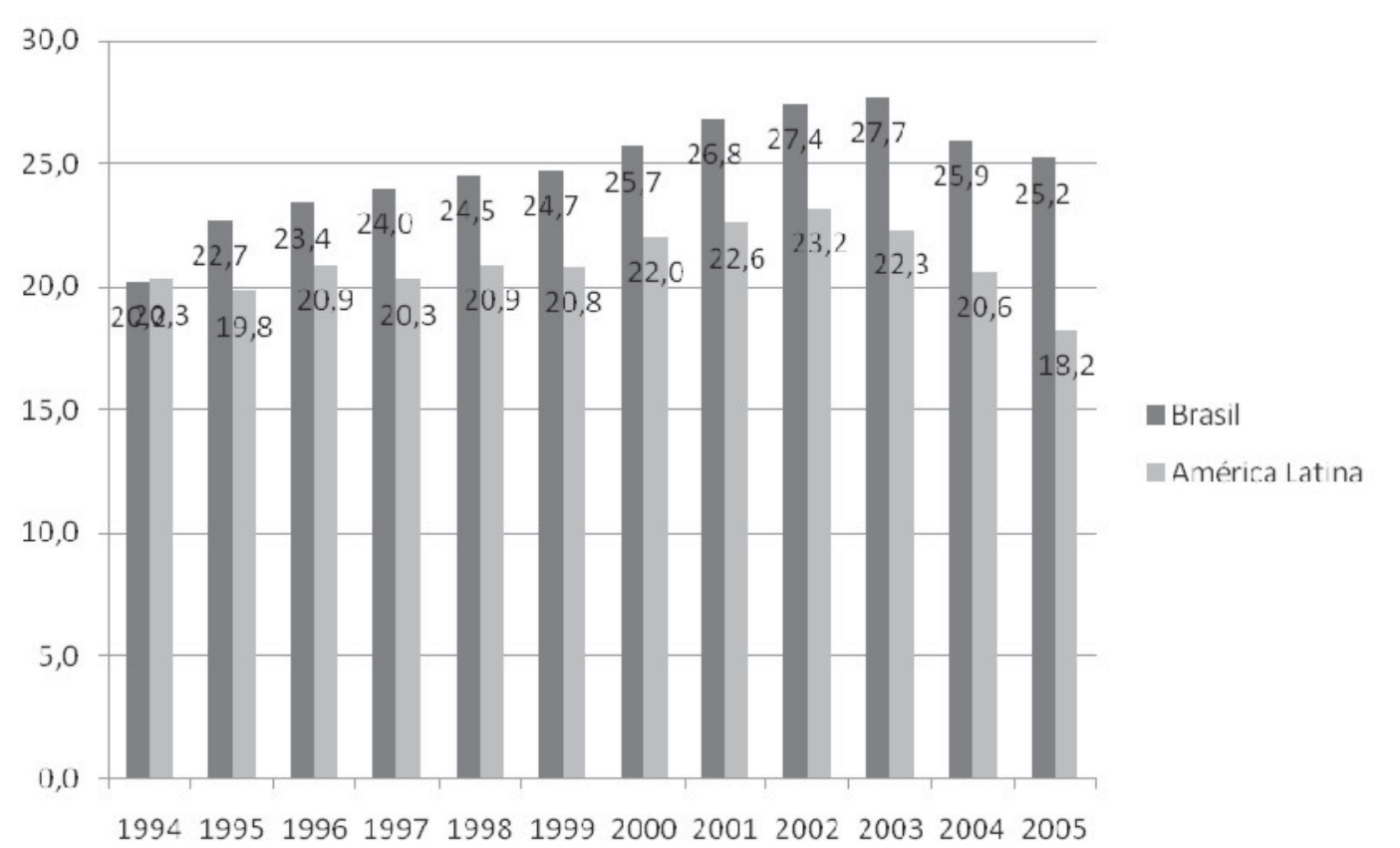

FONTE: Organização Panamericana de Saúde (2012).

Esse sentimento torna-se ainda mais revelador quando contrastado com os dados coletados pelo survey Lapop-Brasil (LAPOP, 2006), administrado pela Vanderbilt University. Tal estudo revela que: i) $43 \%$ da população apóiam, em alguma medida, que as pessoas façam justiça com suas próprias mãos quando o Estado não castiga os criminosos; ii) $40 \%$ da população afirmam que seria justificável os militares tomarem o poder no caso de um excesso de crime sem adequada resposta do aparelho estatal. Esses dados parecem indicar que a população brasileira apóia fortemente medidas de ordem e segurança, assim como medidas autoritárias, quando crime e violência crescem de maneira significativa. Ou seja, quando o indíviduo é um bandido, as dimensões de justiça e reciprocidade parecem ser esquecidas pelos próprios cidadãos, já que ele [bandido] "não é qualquer sujeito incriminado, mas um sujeito por assim dizer 'especial', aquele cuja morte ou desaparecimento podem ser amplamente desejados. Ele é agente de práticas criminais para as quais são atribuídos os sentimentos morais mais repulsivos, o sujeito ao qual se reserva a reação moral mais forte e, por conseguinte, a punição mais dura: seja o desejo de sua definitiva incapacitação pela morte física, seja o ideal de sua reconversão à moral e à sociedade que o acusa" (MISSE et alii, 2010, p. 17).
Logo, os indivíduos classificados nessa categoria são aqueles cujos direitos de cidadania parecem ser negados por um entendimento distorcido da dimensão de solidariedade. É como se nesse caso fosse necessário retribuir, aos indivíduos que infringiram a lei, a violência simbólica que eles infligiram à sociedade com o seu crime. Tal violência, contudo, é diferenciada de acordo com a posição que o "bandido" ocupa na estrutura econômica e na estrutura de status de uma dada sociedade. Esse fenômeno, por sua vez, implica reconhecer uma injustiça dentro do próprio conceito de justiça que se pretende realizar ao aniquilar esse ator político do ponto de vista fático e simbólico. Em última instância, as operacionalizações que os bandidos, em regra, engendram na sociedade brasileira oferecem um exemplo de como, em nome da cidadania, negase a cidadania de maneira injusta e pouco solidária.

Pandolfi (1999) afirma que esse cenário pode ser decorrente da falta de entendimento do conceito de cidadania de maneira global, o que, por sua vez, explica-se pela forma como a cidadania civil institucionalizou-se no Brasil. Esse processo distorcido traduziu-se em uma percepção frouxa dos direitos e das garantias individuais e na inexistência ou ineficácia dos mecanismos para protegê-los. Assim, sob o argumento da eficiência 
absolvem-se as ações policiais que não estão em acordo com os princípios de justiça e solidariedade, entendendo-as como "acidentes de percurso", inevitáveis sob o argumento da proteção. Logo, em diversas situações, a população parece não conceber as dimensões de justiça e solidariedade como duas faces de uma mesma moeda, já que o componente da justiça é muito mais forte do que o componente da reciprocidade.

Portanto, o que se pretende, na seção seguinte, é trazer impressões, abordar questões e explorar alguns paradoxos suscitados a partir dos resultados da III Semana de Visita a Delegacias de Polícia, realizada em outubro de 2009, com o objetivo de auferir-se a qualidade do serviço prestado por essas unidades, a partir da perspectiva do próprio cidadão. Com isso, pretende-se problematizar em que medida as delegacias de polícia institucionalizam o deficit de cidadania, ao prover ao indivíduo um atendimento que não se enquadra dentro dos paradigmas de justiça e solidariedade.

IV. QUAL CIDADANIA EXERCE-SE NO CONTEXTO DAS DELEGACIAS DE POLÍCIA BRASILEIRA?

O argumento a ser desenvolvido nessa seção é que, se não existisse um deficit de cidadania no Brasil, o atendimento prestado pelas delegacias de polícia seria sempre classificado como adequado pelos próprios usuários do serviço, já que cumpriria os requisitos de justiça e solidariedade, de acordo com as definições apresentadas na seção anterior. Ou seja, se no processo de visita às delegacias de polícia os indivíduos encontram constrangimentos econômicos, sociais ou institucionais para o exercício da sua cidadania, esses fatos podem indicar que, no âmbito da Polícia Civil, o deficit de cidadania civil está presente.

Para a realização dessa discussão, serão utilizados os dados quantitativos e qualitativos coletados no âmbito da III Semana de Visitas a Delegacias de Polícia. Conforme destacado anteriormente, essa pesquisa tem como objetivo avaliar a qualidade do atendimento que a Polícia Civil presta aos seus usuários a partir de cinco dimensões: $i$ ) orientação para a comunidade; $i i$ ) condições físicas; iii) tratamento igualitário da população; iv) transparência e prestação de contas e v) condições de detenção.

Em primeiro lugar, a delegacia precisa ser acessível à população. $\mathrm{O}$ indivíduo precisa poder localizá-la imediatamente quando precisa dela. Uma vez na unidade, é necessário saber quais são os procedimentos e documentos que serão requisitados para que a sua queixa possa ser adequadamente registrada. É preciso ainda que uma equipe esteja esperando pela chegada dos indivíduos que desejam registrar crimes ou prestar testemunho de delitos.

Esses são exatamente os critérios avaliados pela Altus no item orientação para a comunidade (Gráfico 5). De maneira geral, os cidadãos consideraram que as delegacias atendem os requisitos estabelecidos e, por isso, avaliam a maioria delas como "adequada". Apenas no item "informações disponíveis sobre como registrar queixas" as unidades visitadas foram classificadas em sua maioria como "inadequada". 


\section{GRÁFICO 5 - CLASSIFICAÇÃO DAS DELEGACIAS DE POLÍCIA VISITADAS EM TERMOS DE ORIENTAÇÃO} PARAACOMUNIDADE

- Totalmente inadequado $\square$ Inadequado $n$ Adequado $\square$ Mais do que adequado $\square$ Excelente

Equipe destinada ao atendimento ao público e/cu registro ce ocorrências

Informações disponíveis sobre como registrar ocorrências e/ou obter serviços públicos

Espaço e equipamentos para servir ao público que chega para registrar ocorrências ou requisitar outros tipos de serviços

Localização da delegacia

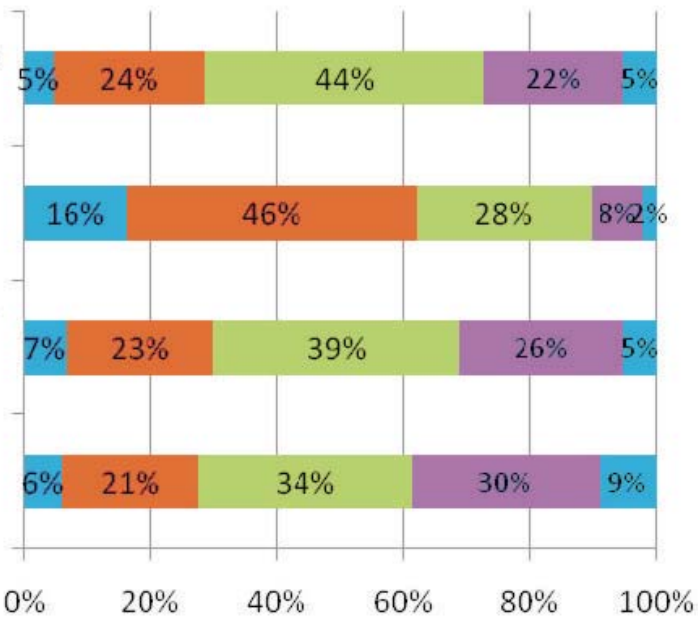

FONTE: Altus (2010).

Quando se procura compreender como, de uma perspectiva empírica, os conceitos de justiça e solidariedade são materializados no item orientação para a comunidade, o ponto de apoio analítico passa a ser como as delegacias percebem quem é o seu usuário.

Considerando os dados coletados pela pesquisa, talvez o exemplo mais interessante da ausência de justiça e solidariedade seja como as delegacias administram o dia do funcionário público, 28 de outubro. Em todas as capitais, as visitas anteriormente agendadas para essa data tiveram de ser reagendadas a pedido dos próprios policiais. Como justificativa, alguns afirmavam que no dia do servidor público as delegacias contam com número reduzido de funcionários (em esquema de plantão, já que se trata de ponto facultativo), o que prejudicaria a avaliação da qualidade do atendimento. Outros alegavam que as delegacias fecham as portas para o atendimento ao público nos feriados e, assim, a visita não poderia acontecer. Essas afirmativas evidenciam que os policiais não levam em conta que pessoas podem ser vítimas de delitos mesmo em feriados e que precisarão do serviço da delegacia de polícia, tornando impossível o exercício da cidadania nessa data.
O dilema sobre quem é o público principal da delegacia também se fez presente na cidade do Rio de Janeiro por outro motivo. Na véspera da Semana de Visitas, o integrante de um importante projeto social foi morto no centro da cidade, após um assalto. Minutos depois do crime, uma viatura da Polícia Militar passou pelo local e, além de não prestar socorro ao ferido, tomou dos ladrões o produto de seu roubo, liberando-os em seguida. Os policiais e os ladrões, presos posteriormente, seriam conduzidos a uma das delegacias sorteadas para a visita. Como as datas coincidiam, o delegado entrou em contato com a coordenação explicando que, devido à tomada de diversos depoimentos de "pessoas importantes", a delegacia seria fechada para atendimento ao público e, por isso, não poderia ser avaliada. Depois de muita insistência, o delegado liberou a visita do grupo, mas a pergunta ficou: o que faz que uma pessoa seja mais importante que as demais, ainda que a situação (no caso, ser vítima de um crime) seja a mesma? Quem é o público da delegacia? As "pessoas importantes" ou todos os cidadãos? Afinal, como dizer que as delegacias são orientadas para a comunidade se elas fecham-se para esta dependendo do momento ou das pessoas que estão envolvidas em uma dada ocorrência? 
Esse caso poderia ser, inclusive, um exemplo do desequilíbrio entre os princípios de justiça e solidariedade, já que a falta de respeito com os direitos dos indivíduos em geral é contrastada com o favorecimento de determinadas "pessoas importantes" que se mostram especialmente dignas de consideração. Esse seria o exemplo privilegiado daquilo que Cardoso de Oliveira denomina de "situação onde se tem pouca justiça no acesso aos direitos, mas onde sobra solidariedade, ainda que excessivamente circunscrita e bem localizada na consideração da pessoa do cidadão que merece reconhecimento" (CARDOSO DE OLIVEIRA, 1995, p. 7).

Portanto, se de maneira geral as delegacias são adequadas em termos de orientação para a comunidade, para vários visitantes, muitas delegacias têm de melhorar o atendimento ao público para tornarem-se acessíveis: "O grupo avaliou inadequadas as condições da delegacia quanto à acessibilidade, faltam elevadores e rampas. Não há informações disponíveis sobre como registrar queixas e/ou obter serviços públicos; e os funcionários não estavam devidamente identificados. Existe um Cartaz na recepção indicando os serviços que a delegacia presta, alguns destes não existem como a brinquedoteca e auditório, estes são usados como depósito de apreensões. O banheiro para o público é único com separação de sexo interno. Possui uma sala grande de espera com um balcão para o primeiro atendimento, no momento sem funcionários, e outro balcão para atendimento propriamente dito, não havia salas separadas para atendimento individual de casos delicados. Os usuários reclamaram da demora no atendimento" (Coordenador da visita ao $83^{\circ}$ Distrito Policial, São Paulo).

Uma vez que o indivíduo consegue ser recebido por um policial em uma delegacia, é necessário que esta conte com mecanismos adequados para atender o cidadão. Logo, no item condições físicas são avaliados: $i$ ) o grau de organização e limpeza da delegacia; $i$ ) o estado de conservação do prédio e da mobília; iii) as condições de trabalho para a equipe da delegacia e, por fim, $i v$ ) a infraestrutura da unidade para vítimas ou testemunhas fazerem o reconhecimento de suspeitos, sem serem identificadas. Em todos os critérios, pelo menos um quarto das delegacias foram classificadas como "mais do que adequadas" ou "excelentes" (Gráfico 6), denotando que, talvez, as condições materiais que viabilizam o exercício da justiça estejam presentes em uma grande parte das delegacias, cabendo aos policiais desenvolverem as habilidades necessárias para viabilizar o item solidariedade.

\section{GRÁFICO 6 - CLASSIFICAÇÃO DAS DELEGACIAS DE POLÍCIA VISITADAS EM TERMOS DE CONDIÇÕES MATERIAIS}

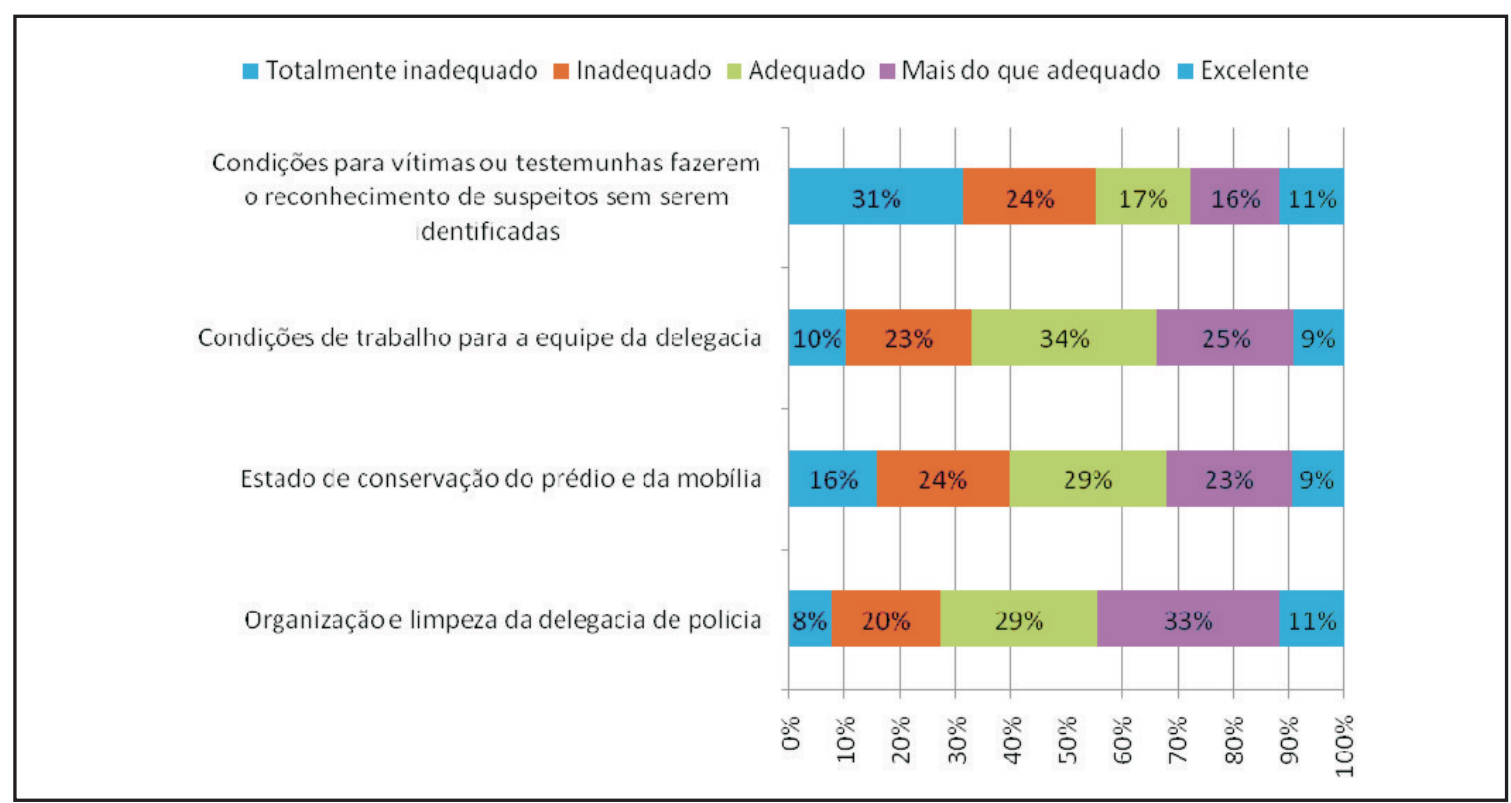

FONTE: Altus (2010). 
Os relatórios qualitativos indicam que, em geral, as delegacias possuem boas instalações e equipamentos em estado razoável de conservação, fatores estes que são importantes para o adequado desempenho do trabalho policial. No entanto, diversos visitantes constataram que várias delegacias ainda reproduzem o estereótipo "repartições sujas, desorganizadas e hostis ao público": "A delegacia é bem equipada, dispõe de bons equipamentos nas salas: computadores, arcondicionado, telefones. Apesar disso, as salas são muito desorganizadas e pequenas. Tem materiais apreendidos espalhados pelas salas e corredores, inclusive na sala do delegado. As armas não têm lugar específico, ficam num armário que oferece pouquíssima proteção. Essas armas, por sinal, já estavam bem velhas. [...] A recepção não é bem estruturada, o balcão e as cadeiras já estão velhos e em mau estado de conservação, tem pouquíssimos cartazes e informativos no mural (apenas referentes a notificações internas da delegacia)" (Coordenador da visita ao $48^{\circ}$ Distrito Policial, Recife).

Nesse contexto, um ponto importante a ser destacado é como a institucionalização de direitos como privilégios desigualmente distribuídos na sociedade brasileira faz com que os próprios visitantes esperem condições materiais diferenciadas dependendo de onde a delegacia está localizada. É como se os mecanismos institucionais de acesso à justiça tivessem que ser diferenciados necessariamente de acordo com as características econômicas e sociais da população a que essas estruturas servem. Ou, para considerar o elemento da solidariedade, é como se os mecanismos institucionais de administração de conflitos, para atenderem ao ideal de reciprocidade, tivessem de "dar aos pobres a sua pobreza e aos ricos a sua riqueza"18. Essa idéia parece estar especialmente ilustrada nas seguintes assertivas:

- "Pensávamos que as condições físicas seriam melhores por estar em um bairro nobre da cidade" (Coordenador da visita ao $224^{\circ}$ Distrito Policial, Brasília).

- "A equipe acreditava antes da visita que esta delegacia, por se situar em uma região nobre, estaria equipada com todos os recursos

18 Frase de Roberto Lyra Filho no documentário $O$ direito achado na rua. Para mais informações, cf. Lyra Filho (2012). disponíveis para o trabalho, mas percebeu um quadro oposto durante a visita. Faltavam vários equipamentos e pessoal para o trabalho" (Coordenador da visita ao $66^{\circ}$ Distrito Policial, Belo Horizonte).

- “A delegacia causou uma ótima impressão. Talvez por se tratar de uma região empobrecida do município de São Paulo, não se esperava uma delegacia com condições tão adequadas de atendimento e tão bonita e organizada" (Coordenador da visita ao $100^{\circ}$ Distrito Policial, São Paulo).

- "Para alguns dos visitantes, a visita serviu apenas para confirmar suas expectativas negativas sobre o local, para outros a situação era pior do que imaginavam. As condições do prédio e da carceragem impressionaram negativamente. Além disso, acreditam que o fato de estar localizada num bairro pobre da cidade justifica o descaso e reflete a discriminação com a população mais pobre" (Coordenador da visita ao $105^{\circ}$ Distrito Policial, Recife).

Em seguida, a pesquisa avalia a capacidade da delegacia em oferecer um tratamento igualitário à população, sem viés de raça, gênero, idade e orientação sexual. A idéia é que a delegacia deve, impreterivelmente, possuir serviços e equipamentos que sejam capazes de garantir que públicos diferenciados recebam tratamento igualitário. Nesse quesito são avaliados os serviços disponíveis para grupos específicos (mulheres, idosos e pessoas com dificuldade de locomoção); para pessoas com necessidades especiais; para mulheres e, ainda, a existência de espaços e equipamentos para entrevistar vítimas de crime em casos em que a privacidade é importante.

É importante destacar que, especialmente em comparação com os critérios apresentados anteriormente, um quantitativo substancial de delegacias foi classificado como totalmente inadequado. Se pelo menos um quarto das unidades visitadas destacavam-se em termos de condições materiais, nesse caso, pelo menos um quarto das delegacias foram consideradas como "totalmente inadequada" em termos de tratamento igualitário (Gráfico 7). 

IGUALITÁRIO

- Totalmente inadequado $\square$ Inadequado $n$ Adequado $\square$ Mais do que adequado $\square$ Excelente

Serviços e/ou encaminhamentos disponíveis exclusivamente para grupos específicos

Serviços disponíveis para pessoas com necessidades especiais

Condições dos espaços e equipamentos dedicados especificamente às mulheres

Espaços e equipamentos para entrevistar vítimas ou testemunhas de crimes em casos em que a privacidade é importante

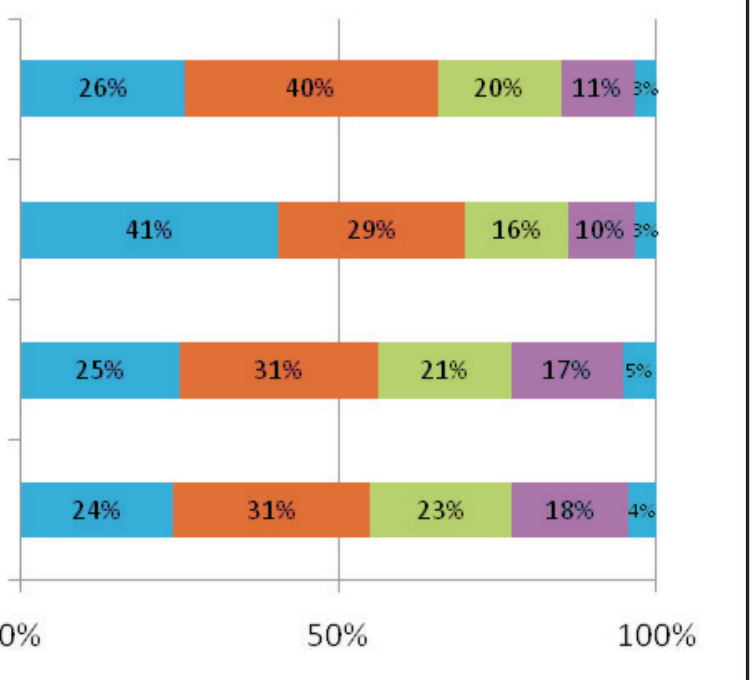

FONTE: Altus (2010).

Os visitantes consideraram que a maioria das delegacias não oferece tratamento igualitário ao público que a procura. Eles notaram a ausência de informações, serviços e encaminhamentos para pessoas ou grupos considerados como aqueles em condição vulnerável, como crianças, mulheres, homossexuais, deficientes físicos e idosos. Novamente, percebeu-se aquilo que Cardoso de Oliveira (1995) denomina como excesso de solidariedade em relação a determinados grupos: "O que muito impressionou aos visitantes foram os comentários de ambos policiais que reconheceram que a abordagem na zona sul deve ser diferenciada do que na zona norte e percebeuse também muito preconceito em relação a usuários de entorpecentes e dependentes químicos. Relataram que a descriminalização da maconha fez com que os policiais fossem desmoralizados, assim como o tratamento igualitário a prostitutas e travestis" (Coordenador da visita ao $123^{\circ}$ Distrito Policial, Rio de Janeiro).

Da mesma forma, foi observado que várias delegacias não possuem espaços específicos para entrevistar vítimas ou testemunhas de crimes, nos casos em que a privacidade é importante. A ausência desse elemento encontra-se diretamente em desacordo com a idéia de justiça, como cunhada por Fraser (2009), já que, em razão da ausência de determinados elementos institucionais, o indivíduo não é capaz de exercer plenamente seus direitos enquanto ator político: "Não havia serviços especializados disponíveis, tais como psicólogos, assistentes sociais, atendimento especializado para mulheres, ou local para se deixar crianças. Nem funcionários nem presos estavam identificados por meio de crachás. Também foi notado que, no local onde o boletim de ocorrência é registrado, não há privacidade alguma para a vítima. Conversamos com um casal, que disse ter demorado mais de duas horas para que fossem atendidos" (Coordenador da visita ao $85^{\circ}$ Distrito Policial, São Paulo).

Por fim, uma vez realizado o atendimento, a população deve ser informada tanto dos desdobramentos do seu registro como da existência de mecanismos institucionais específicos para registro de queixas e desvios de conduta dos policiais. Desse modo, nesse item, são avaliadas ainda a adequada identificação da equipe da delegacia e a disponibilidade de informações sobre o trabalho que a delegacia realiza no combate ao crime. Os resultados indicam que essa é a dimensão na qual as delegacias tiveram pior desempenho, já que em diversos quesitos metade das unidades visitadas foram classificadas como totalmente inadequadas (Gráfico 8). 


\section{GRÁFICO 8-CLASSIFICAÇÃO DAS DELEGACIAS DE POLÍCIA VISITADAS EM TERMOS DE} TRANSPARÊNCIAE PRESTAÇÃO DE CONTAS

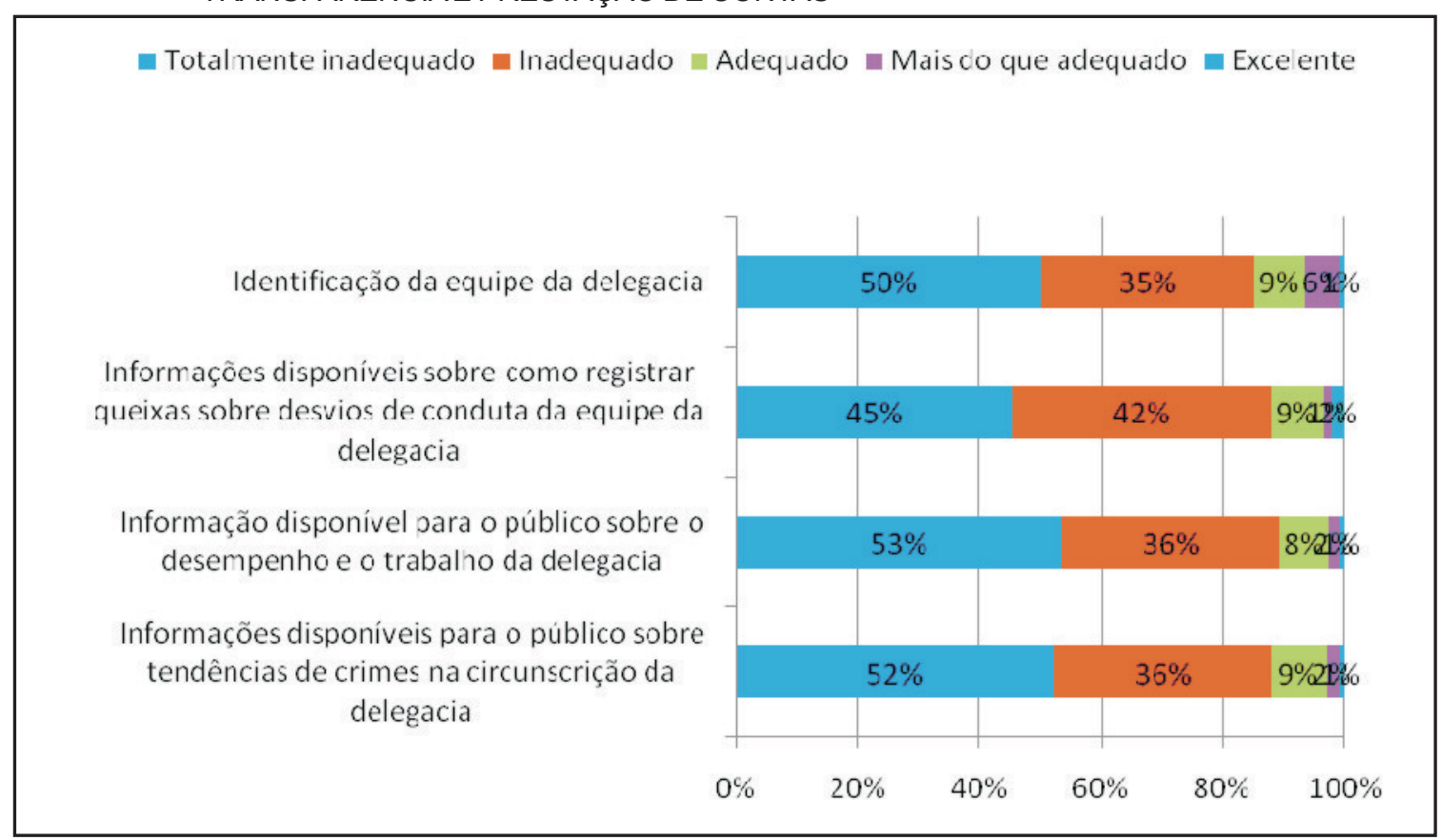

FONTE: Altus (2010).

O item transparência e prestação de contas foi aquele em que os visitantes fizeram as maiores críticas. De acordo com eles, os problemas começam logo na entrada da delegacia. Como poucos são os exemplos de policiais uniformizados e com crachás, destacando qual a função que o indivíduo exerce na unidade, a primeira dificuldade do usuário é identificar quem é o policial: "Ao entrarmos na delegacia havia um bom movimento já que algumas pessoas estavam sendo atendidas. Os policiais estavam atendendo várias pessoas e nós tivemos dificuldade de identificar quem eram os policiais e quem eram os civis já que aqueles não tinham nenhuma identificação como crachá ou uniforme - apenas posteriormente vimos que havia uma mulher com uma camisa da Polícia Civil, porém esta não estava na recepção quando chegamos. Neste momento ocorreu um fato curioso: quando me aproximei da mesa de recepção e logo percebi quem poderia ser um possível policial me identifiquei a ele e perguntei sobre quem poderia nos receber. Eles estavam atendendo muitas pessoas ao mesmo tempo e tivemos que esperar algum tempo. Mas neste primeiro momento em que abordei o policial e conversamos sobre quem poderia nos atender, entra na delegacia um homem de terno, que parecia ser um advogado, e me pede uma informação, como se eu fosse um policial, justamente porque não havia uma identificação clara e em torno de toda aquela mistura entre policiais e civis, tudo ficou ainda mais confuso" (Coordenador da visita ao $228^{\circ}$ Distrito Policial, Belo Horizonte)

O exemplo acima é revelador do que pode acontecer quando a equipe da delegacia não se encontra previamente identificada. Esse quadro torna-se ainda mais dramático em cenários onde não existe nenhum tipo de cartaz ou informativo sobre como registrar queixas em relação ao serviço oferecido. De acordo com os visitantes, caso o público pergunte sobre a existência de tal órgão, os policiais encaminham para o delegado as queixas, indicando uma forte dose de corporativismo. "O discurso do delegado soou estranho, voltado para nos convencer sobre sua dedicação, a qualidade de seu trabalho e índole moral. Algumas cenas mostraram o contrário, como, por exemplo, a omissão dele diante de um investigador que destratou um rapaz em averiguação na delegacia na frente da equipe de visitas, ou a falta de cartazes sobre ouvidoria ou corregedoria acompanhada do discurso do 
delegado de que isso é desnecessário, pois se alguém tiver reclamação a fazer, tem de ter coragem para falar com ele" (Coordenador da visita ao $88^{\circ}$ Distrito Policial, São Paulo).

No que diz respeito à prestação de contas, o maior problema não é a dificuldade em produzirse a informação, mas em construir uma visão de que esta é de interesse público e não de interesse privado. Os policiais temem a publicidade das informações especialmente pelo que ela pode implicar em termos de cobrança da comunidade por maior efetividade da ação policial. "Os policiais argumentam que um mapa criminal facilitará a informação dos criminosos e irá alardear a população inutilmente. Mas o argumento é frágil, uma vez que não possibilita à população qualquer tipo de informação sobre crimes cometidos e/ou orientações sobre como se comportar diante de algum tipo de delito. Além disso, a delegacia não apresenta informativos quanto ao número de casos solucionados, inquéritos concluídos ou afim. É importante ressaltar que há resistência dos policiais nesse tipo de esclarecimento à população" (Coordenador da visita ao $124^{\mathrm{a}}$ Distrito Policial, Rio de Janeiro).

Algumas delegacias justificam o segredo de tais informações e, ainda, a não identificação dos policiais como uma prática que tem por objetivo garantir a "segurança" da própria população usuária desse serviço. "O distrito policial conta com um mapa de sua circunscrição no saguão de atendimento. No entanto, não conta com qualquer informação a respeito de: tendências de crime na região; desempenho e trabalho da delegacia; e, informações de como relatar desvios de conduta da equipe policial. O delegado relatou que não pode expor na delegacia, os dados sobre os locais de crime na região por que: primeiro, o público não ia mudar os seus hábitos cotidianos; segundo, seria contra produtivo, uma vez que, os criminosos teriam acesso a esta informação e saberiam onde não agir; terceiro, os comerciantes se sentiriam prejudicados, pois caso o público mudasse os seus hábitos, ele poderia deixar de consumir em determinados locais. Cabe destaque que os funcionários da delegacia não estavam uniformizados e não estavam identificados. O delegado disse que os funcionários não utilizavam o 'cagueta', por motivos de segurança" (Coordenador da visita ao $124^{\circ}$ Distrito Policial, São Paulo).

Em suma, os dados coletados no item "transparência e prestação de contas" evidenciam que os indivíduos que querem conhecer melhor o que a polícia faz a partir dos seus próprios dados, ou ainda, aqueles que querem entender a dinâmica da criminalidade na localidade onde residem são impedidos de realizar tais atividades por inúmeros constrangimentos institucionais criados pelos próprios policiais. Ou seja, o elemento justiça a que se referia Cardoso de Oliveira (1995) não se encontra presente nessa dimensão. Por outro lado, aqueles indivíduos que sentirem que a polícia não oferece um serviço solidário o suficiente também não encontram meios de reclamar ou expressar sua insatisfação, já que os próprios policiais procuram bloquear ao limite o acesso a tais canais institucionais.

Por fim, são consideradas as condições de detenção. Esse tema é inserido no formulário porque, em diversos lugares do mundo, a polícia ainda se ocupa da guarda de presos e, por isso, é importante compreender como essa instituição trata esses indivíduos do ponto de vista dos ideais de justiça e solidariedade. Logo, nesse item, são avaliadas questões como: condições sanitárias das áreas de detenção; condições e espaços para advogados, familiares ou amigos visitarem detentos; identificação dos detentos e condições de segurança da área de detenção.

Mais uma vez, os dados coletados indicam como as delegacias brasileiras possuem dificuldades em operacionalizar um tratamento justo e solidário aos detentos. Por exemplo, as condições sanitárias da área de detenção foram avaliadas como totalmente inadequadas em $50 \%$ das unidades visitadas. Se não há higiene para encarceramento do preso, não há que se falar em espaços para esse indivíduo conviver com outras pessoas ou mesmo na sua identificação. Logo, os dados a seguir apenas confirmam essa asserção (Gráfico 9). 
GRÁFICO 9 - CLASSIFICAÇÃO DAS DELEGACIAS DE POLÍCIA VISITADAS EM TERMOS DE CONDIÇÕES DE DETENÇÃO

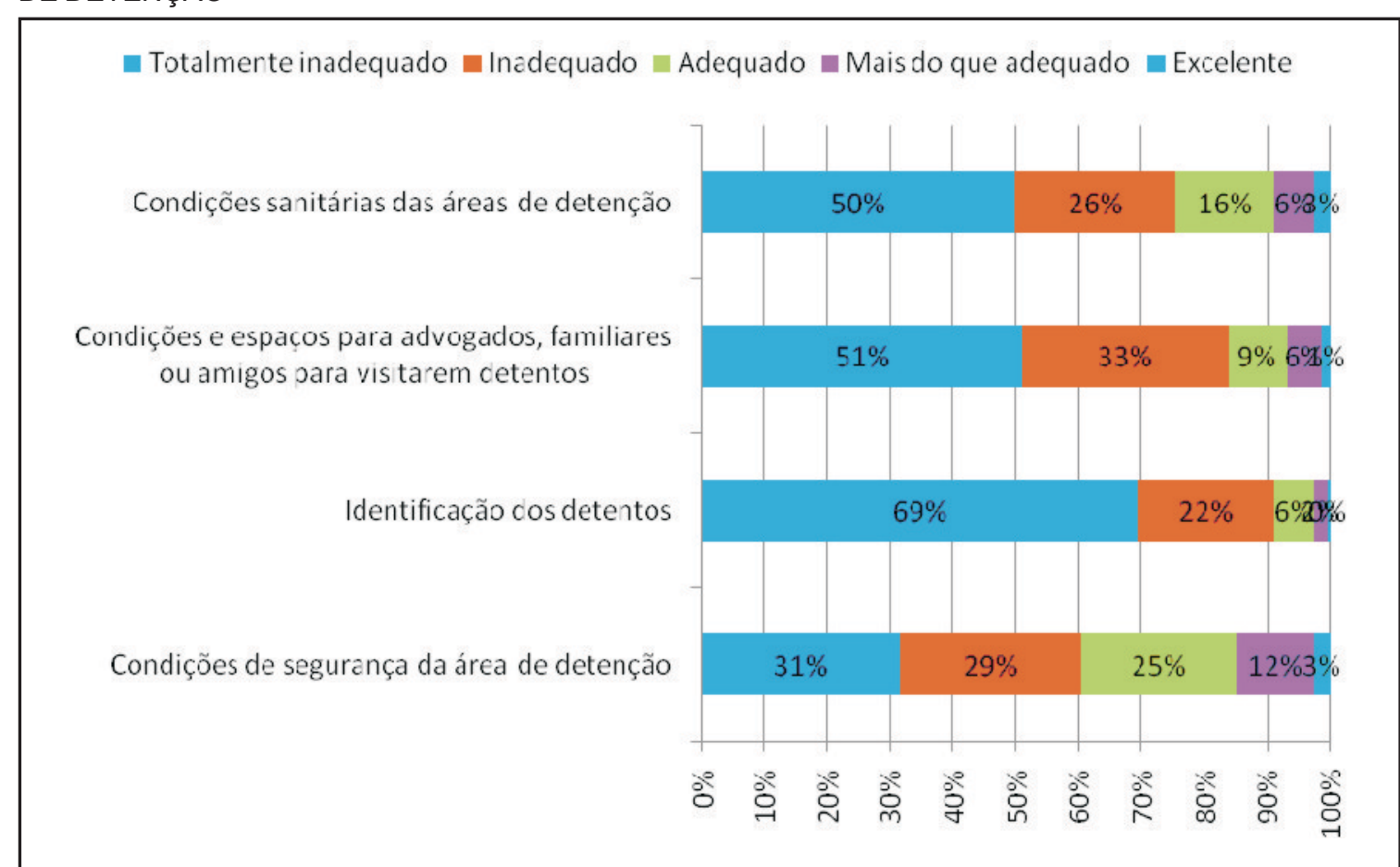

FONTE: Altus (2010).

Os relatórios narrativos destacam que as condições carcerárias são sofríveis e estão em desacordo com as regras mínimas para o encarceramento de presos, estabelecidas pelos tratados internacionais de direitos humanos: "Os detentos não apresentavam algum tipo de identificação, não existe uma sala adequada para receberem os advogados e familiares, não existe visita, somente no final de cada semana e que os familiares podem levar algum material de limpeza individual. Durante a visita, pode-se notar as condições precárias das celas, não apresentavam nenhum tipo de limpeza, estavam superlotadas, ventilação mínima e o banheiro inadequado" (Coordenador da visita ao $18^{\circ}$ Distrito Policial, Belém). "Os presos são mantidos em uma pequena cela, que mais parece uma jaula, no mesmo ambiente onde são registradas as ocorrências. $\mathrm{O}$ espaço é apertado, pouco iluminado e apesar de ter três cadeados, não parece muito seguro. Não há banheiro específico nem local para visitas" (Coordenador da visita ao $227^{\circ}$ Distrito Policial, Belo Horizonte).

Um problema apontado foi a dificuldade das delegacias distritais em administrar a questão da mulher que, presa em flagrante, deve ser detida em alguma cela ou sala de custódia. Esse fenômeno é um grande problema para as delegacias porque, ainda hoje, a maioria da população carcerária é composta por homens e, por isso, poucos são os casos de celas destinadas especificamente às mulheres. Em situações como essas, o improviso parece ser a regra. "As mulheres, o comissário nos informou que não são encaminhadas para o xadrez, costumam ser algemadas em alguma sala até serem transferidas" (Coordenador da visita ao $4^{\circ}$ Distrito Policial, Recife).

Problema semelhante é vivenciado nas delegacias que não contam com carceragens, mas que devem administrar a questão do indivíduo preso em flagrante. Nesse caso, o detento é algemado em instalações da unidade, devendo permanecer em pé, sem a possibilidade de ir ao banheiro ou se alimentar. "A delegacia não possui carceragem. Os presos em flagrante permanecem algemados a uma barra de ferro em um banco de concreto até que todo o procedimento seja feito. Essa estrutura está localizada no corredor da delegacia" (Coordenador da visita ao $14^{\circ}$ Distrito Policial, Goiânia). 
No caso das condições de detenção, embora os regulamentos já publicados sobre o tema sejam claros e precisos a respeito de como proceder perante todos os "tipos" de presos (provisórios, flagrante, mulheres, entre outros), os dados coletados indicam que, na prática rotineira, cada delegacia administra o fenômeno de maneira diferenciada, mas sempre com pouca preocupação se o atendimento destinado ao preso coaduna-se com os critérios de justiça e solidariedade.

Portanto, de maneira geral, o que os dados quantitativos e qualitativos parecem evidenciar é a precariedade da cidadania brasileira no âmbito da discussão sobre acesso à justiça e relações com a polícia. Essas informações sugerem não apenas um desequilíbrio entre as noções de justiça e solidariedade, como também a impossibilidade de traduzir esses conceitos em práticas na rotina das delegacias de polícia de todo o Brasil.

A análise apresentada indica que a postura discriminatória da polícia revela-se em detalhes quando se observa a rotina das delegacias de polícia: os problemas vão desde a ausência de uma equipe preparada para receber quem procura a unidade até a linguagem cifrada ou bacharelesca dos policiais que impedem que o cidadão comum compreenda o que está ocorrendo.

Por fim, é interessante destacar que, na década de 1980, Fischer, após extenso trabalho de campo nas delegacias de polícia de São Paulo, afirmou que diversos policiais consideram que o linguajar e o tratamento ofensivo correspondem ao padrão de relacionamento com o qual o povo está habituado e, por isso, muitos desses agentes não consideravam que as condições físicas das carceragens fossem precárias, posto que estas assemelhavam-se àquelas que os detentos viviam. Ao final, a autora concluía dizendo que "o serviço policial segue muito pouco as prescrições legais e os regulamentos, permitindo que o arbítrio, o instinto e o quadro de valores dos seus agentes determinem efetivamente a sua ação" (FISCHER, 1985, p. 41).

Quase 30 anos após a publicação dessa primeira pesquisa, os resultados coletados pela Altus não foram muito diferentes, indicando que a dificuldade das delegacias de polícia em viabilizar a institucionalização das idéias de justiça e solidariedade seja, talvez, algo histórico e não circunscrito à realidade dos anos 2000 .

\section{CONCLUSÕES: AS DELEGACIAS DE POLÍCIA COMO ESPAÇO PARA O (NÃO) EXERCÍCIO DA CIDADANIA}

A proposta deste artigo foi verificar como as delegacias de polícia equacionam ou não os conceitos de justiça e solidariedade, já que a combinação desses elementos indica a existência da cidadania ou do seu deficit.

O ponto de partida da discussão foi a constatação de que, no Brasil, a transição da ditadura militar para a democracia foi acompanhada da explosão de conflitos sociais de várias ordens e que as organizações responsáveis pela administração institucional desses conflitos permaneceram inalteradas, sendo realizada pelos policiais como o faziam há anos. Os dados indicam que durante a transição para o Estado de Direito e ao longo do processo de consolidação democrática todas as modalidades de crime cresceram, com especial destaque para os homicídios dolosos. Apesar do aumento de tais violações (demonstrado pelos gráficos 1 e 2), a polícia permaneceu operando como fazia há décadas, sem preocuparse em prestar um atendimento de melhor qualidade aos seus usuários.

De acordo com vários autores ${ }^{19}$, durante todo o período 1980-1990, o que se observou foi a ausência de uma agenda de reforma da segurança pública em geral e da polícia em especial, o que fez que as propostas do período ficassem confinadas aos confrontos políticos partidários e de opiniões, cuja maior expressão foi o embate entre políticas de direitos humanos e políticas de lei e ordem. Do ponto de vista do funcionamento cotidiano das organizações policiais, desde os anos 1990, as pesquisas realizadas sobre o tema têm indicado que as delegacias de polícia podem ser classificadas em dois grupos: as que respeitam os direitos humanos e as que agem ao arbítrio da lei, com a justificativa de que o mais importante é manter a ordem (KANT DE LIMA, MISSE \& MIRANDA, 2000).

Logo, com o objetivo de verificar como a Polícia Civil realiza, na atualidade, o atendimento inicial aos indivíduos que procuram os seus serviços e como os cidadãos percebem esse

19 Como apresentado na revisão de Barreira e Adorno (2010). 
atendimento, os dados coletados no âmbito da III Semana de Visitas a Delegacias de Polícia foram utilizados como base empírica dessa reflexão. Esse projeto reúne informações quantitativas e qualitativas acerca de como as delegacias de polícia encontram-se em termos de orientação para a comunidade, condições materiais, tratamento igualitário do público, transparência e prestação de contas e condições de detenção na perspectiva do próprio cidadão, já que é ele quem visita as unidades e preenche o formulário desenvolvido pela Altus.

Utilizando as informações coletadas por meio do formulário da Altus, procurou-se problematizar como a qualidade do atendimento prestado pelas delegacias de polícia pode ajudar no entendimento da dificuldade de compatibilizarem-se, no Brasil, os ideais de justiça e solidariedade que, em conjunto, formam a ossatura do conceito de cidadania, como postulado por Cardoso de Oliveira (1995). Logo, a primeira pergunta que esse artigo procurou responder foi o que os dados coletados durante a Semana de Visitas a Delegacias de Polícia significam em termos da capacidade da Polícia Civil brasileira em institucionalizar o conceito de cidadania civil.

A definição de cidadania civil, por sua vez, foi operacionalizada a partir de dois termos principais: i) justiça, entendida como a percepção do indivíduo de que, independentemente de sua situação econômica ou de seu status social, ele será capaz de realizar-se plenamente como sujeito que integra uma comunidade, sem nenhum tipo de constrangimento institucional; ii) solidariedade, compreendida como a percepção que o indivíduo faz da existência de reciprocidade na relação que ele possui com os entes públicos. Logo, seria possível afirmar que as delegacias de polícia brasileiras são capazes de viabilizar o exercício da cidadania civil se os indivíduos que a procuram entendem que estão recebendo um tratamento justo e solidário.

De um ponto de vista ideal, se justiça e solidariedade estivessem presentes na realidade das delegacias visitadas, estas seriam avaliadas como adequadas em uma escala de pontuação que varia entre (1) totalmente inadequada, (2) inadequada, (3) adequada, (4) mais do que adequada e (5) excelente. Contudo, os resultados apresentados são bastante distintos, tanto quando as unidades são comparadas com as demais existentes na região, como quando as regiões são comparadas entre si. Em geral, as delegacias brasileiras são classificadas como inadequadas (Tabela 3 ). Contudo, dentro de cada localidade, as pontuações máximas e mínimas, bem como o valor do desvio padrão apresentam uma idéia de como essas medidas são discrepantes. Por exemplo, no Rio de Janeiro a variação inclui desde delegacias classificadas como totalmente inadequadas (36 pontos) até delegacias classificadas como excelentes (96 pontos). Quando a comparação é feita entre regiões, destaca-se a discrepância entre as delegacias de Belém do Pará (no limiar de serem classificadas como totalmente inadequadas) e as delegacias de Brasília (adequadas).

TABELA3 - ESTATÍSTICAS DESCRITIVAS DAS AVALIAÇÕES REALIZADAS, POR REGIÃO

\begin{tabular}{|l|c|c|c|c|c|}
\hline \multicolumn{1}{|c|}{ CIDADE } & $\begin{array}{c}\text { NÚMERO } \\
\text { DE CASOS }\end{array}$ & $\begin{array}{c}\text { VALOR } \\
\text { MÍNIMO }\end{array}$ & $\begin{array}{c}\text { VALOR } \\
\text { MÁXIMO }\end{array}$ & MÉDIA & $\begin{array}{c}\text { DESVIO- } \\
\text { PADRÃO }\end{array}$ \\
\hline Belém & 21 & 27 & 50 & 38 & 7 \\
Belo Horizonte & 21 & 34 & 61 & 49 & 9 \\
Brasília & 21 & 38 & 73 & 56 & 9 \\
Fortaleza & 21 & 23 & 67 & 45 & 11 \\
Goiânia & 21 & 30 & 52 & 39 & 5 \\
Porto Alegre & 21 & 33 & 65 & 45 & 9 \\
Recife & 21 & 25 & 52 & 41 & 5 \\
Rio de Janeiro & 43 & 36 & 96 & 54 & 13 \\
São Paulo & 42 & 30 & 69 & 51 & 9 \\
Total & 235 & 23 & 96 & 48 & 11 \\
\hline
\end{tabular}

FONTE: Altus (2010). 
A segunda pergunta que o artigo procurou responder foi em que medida os resultados apresentados pela Semana de Visitas parecem indicar dilemas a serem superados. Para responder a essa questão cumpre destacar que a metodologia da pesquisa baseia-se nos procedimentos da etnometodologia, ou seja, no acompanhamento das práticas sociais dos policiais a partir de um instrumento especialmente desenvolvido para acoplar as distintas atividades que uma pesquisa ação dessa natureza envolve, quais sejam, a demanda de que o pesquisador contribua diretamente para a ação e a reflexão dos objetivos da Polícia Civil e dos meios de implementá-los (FISCHER, 1985, p. 12).

As citações retiradas dos relatórios narrativos de distintas localidades indicam que os dilemas, especialmente, quanto a quem é o público da delegacia e como este deve ser tratado de maneira diferenciada dependendo do seu perfil (ou com excesso de solidariedade, como afirmado por Cardoso de Oliveira (1995)) são uma decorrência direta dos usos que os policiais fazem de suas prerrogativas institucionais.

Em certa medida, esses relatos apenas confirmam os escritos pioneiros de Paixão (1982), reafirmados recentemente por Barreira e Adorno (2010, p. 324). Utilizando as perceptivas desses autores, as situações com as quais os cidadãos depararam-se no decorrer da III Semana de Visitas ocorrem porque a ação dos policiais dá-se em ambientes institucionais caracterizados por frágeis mecanismos de inspeção, por generalização do modelo patrimonial de organização e pela ausência de articulação entre estruturas formais e atividades práticas. O resultado é que as tarefas de investigação e repressão orientam-se por uma espécie de "lógica-em-uso" nos meios policiais, que compreendem um estoque de conhecimento baseado em categorias estereotipadas sobre quem são os criminosos, onde se concentram e como agem, o que, por sua vez, estimula a criminalização do comportamento justamente dos grupos sociais pouco preparados para ter assegurados direitos civis contra o arbítrio das organizações policiais.

Logo, os relatos (científicos dos cidadãos que participaram da Semana de Visitas) sobre a maneira como a Polícia Civil vem agindo cotidianamente perante os cidadãos que a procuram, espontaneamente, para formalizar suas queixas, demonstram o desequilíbrio entre os conceitos de justiça e solidariedade que estruturam a ideia de deficit de cidadania civil.

No que diz respeito ao elemento justiça, em diversas situações os próprios usuários esperam que o tratamento que a polícia dispensa ao indivíduo seja diferenciado dependendo de sua situação socioeconômica. Parece que eles já se acostumaram às limitações institucionais apresentadas em razão das condições socioeconômicas ou de classe do cidadão que procura a polícia. Os relatórios narrativos, por sua vez, surpreenderam ao demonstrar como o atendimento prestado era contraintuitivo: nos bairros mais pobres, foi possível encontrar delegacias com condições adequadas de atendimento, enquanto nos locais mais ricos, nem sempre as delegacias eram bem equipadas.

No que se refere à solidariedade diferenciada, os próprios policiais acham justificável que o atendimento realizado nas áreas mais nobres da cidade seja distinto do que ocorre na zonas periféricas. Logo, os constrangimentos econômicos e sociais não são, na visão dos próprios policiais, compensados por uma estrutura institucional adequada, mas são reificados por esta.

Contudo, a dificuldade em eqüalizar-se justiça e solidariedade aparece de maneira especialmente interessante quando se constata que as deficiências das delegacias brasileiras concentram-se nos itens "transparência e prestação de contas" e "condições de detenção". Parece evidente que alguns indivíduos têm mais acesso a um tratamento de acordo com as regras constitucionais e outros, em razão de seu perfil, acabam sendo tratados de maneira diferenciada.

Portanto, o que as informações coletadas ao longo da III Semana de Visita a Delegacias de Polícia evidenciam é a dificuldade em institucionalizar um tratamento justo e igualitário para toda a população. Tanto os policiais, como os próprios usuários, justificam a existência de particularismos e de graus diferenciados de solidariedade como mecanismo de (in)justiça, posto que permite tratar desigualmente os desiguais. 
Ludmila Ribeiro (ludmila.ribeiro@gmail.com) é Doutora em Sociologia pelo Instituto Universitário de Pesquisas do Rio de Janeiro (Iuperj) e Pesquisadora da Fundação Getúlio Vargas (FGV).

Julita Lemgruber (jlemgruber@candidomendes.br) é Mestre em Sociologia pelo Instituto Universitário de Pesquisas do Rio de Janeiro (Iuperj) e Professora da Universidade Cândido Mendes (UCAM).

Klarissa Almeida Silva (silva.klarissa@gmail.com) é doutoranda em Ciências Humanas pela Universidade Federal do Rio de Janeiro (UFRJ).

\section{REFERÊNCIAS BIBLIOGRÁFICAS}

BARREIRA, C. \& ADORNO, S. 2010. A violência na sociedade brasileira. In: MARTINS, C. B. \& MARTINS, H. H. T. S. (orgs.). Horizontes das Ciências Sociais no Brasil: Sociologia. São Paulo: Associação Nacional de PósGraduação em Ciências Sociais.

CANO, I. 2006. Políticas de seguridad pública en Brasil: tentativas de modernización y democratización versus la guerra contra el crimen. Sur, São Paulo, v. 3, n. 5. Disponível em: http://www.surjournal.org/esp/index5.php. Acesso em: 15.maio.2012.

CARDOSO DE OLIVEIRA, L. R. 1995. Entre o justo e o solidário: os dilemas dos direitos de cidadania no Brasil e nos EUA. Revista Brasileira de Ciências Sociais, São Paulo, v. 11, n. 31, p. 67-81. Disponível em: http:// www.anpocs.org.br/portal/publicacoes/ rbcs_00_31/rbcs31_04.htm. Acesso em: 15.maio. 2012 .

CHEVIGNY, P. 2002. Definiendo el rol de la policía en América Latina. In: MÉNDEZ, J.; O'DONNEL, G. \& PINHEIRO, P. S. (eds.). La (in)efectividad de la ley y la exclusión en América Latina. Buenos Aires: Paidós.

COMPARATO, F. K. 1981. Segurança e democracia. In: LAMOUNIER, B.; WEFFORT, F. \& BENEVIDES, M. V. (orgs.). Direito, cidadania e participação. São Paulo: T. A. Queiroz.

COUTINHO, C. N. 2000. Notas sobre cidadania e modernidade. In:_. Contra a corrente. Ensaios sobre democracia e socialismo. São Paulo: Cortez.

DAMMERT, L.; SALAZAR, F.; MONTT, C. \& GONZALEZ, P.A. 2010. Crimen e inseguridad: indicadores para las Américas. Santiago de Chile: Banco Interamericano de Desarrollo.

DE LA PAZ, G. 2004. Citizenship Identity and Social Inequality. Ciudad de Mexico: Instituto
Federal Electoral. Disponível em: http:// www.civiced.org/pdfs/delaPazGabriel.pdf. Acesso em: 15.maio.2012.

FISCHER, R. M. 1985. O direito da população à segurança. São Paulo: Centro de Estudos de Cultura Contemporânea.

FRASER, N. 2009. Reenquadrando a justiça em um mundo globalizado. Lua Nova, São Paulo, n. 77, p. 11-39. Disponível em: http:// www.scielo.br/pdf/ln/n77/a01n77.pdf. Acesso em: 15.maio.2012.

FRÜHLING, H. 2009. Research on Latin American Police: Where Do We Go from Here? Police Practice and Research, Abingdon, v. 10, n. 5-6, p. 465-482, Oct.-Dec.

GIDDENS, A. \& TURNER, J. 1999. Teoria Social hoje. São Paulo: UNESP.

KANT DE LIMA, R. 1995. A polícia da cidade do Rio de Janeiro: seus dilemas e paradoxos. Rio de Janeiro: Forense.

KANT DE LIMA, R.; MISSE, M. \& MIRANDA, A. P. M. 2000. Violência, criminalidade, segurança pública e justiça criminal no Brasil: uma bibliografia. BIB, Rio de Janeiro, v. 50, p. 45124.

LEITE, M. P. 2000. Between Individualism and Solidarity: Dilemmas of Politics and Citizenship in Rio de Janeiro. Revista Brasileira de Ciências Sociais, São Paulo, v. 15, n. 44, p. 43-90. Disponível em: http://www.scielo.br/ scielo.php?script=sci_pdf\&pid=S010269092000000300004\&lng=en\&nrm=iso\&tlng-pt. Acesso em: 15.maio.2012.

LEMGRUBER, J.; CANO, I. \& MUSUMESCI, L. 2003. Quem vigia os vigias? Rio de Janeiro: Record.

LIMA, R. K. 2004. Atributos raciais no funcionamento do sistema de justiça criminal paulista. 


\section{BETWEEN JUSTICE AND SOLIDARITY: CITIZENSHIP FROM WITHIN THE BRAZILIAN CIVIL POLICE FORCE}

\section{Ludmila Ribeiro, Julita Lemgruber and Klarissa Almeida Silva}

Our paper discusses the role of the Civil Police within a democratic scenario in which citizenship is supposed to be completely institutionalized. For these purposes, we use quantitative and qualitative data on 235 different Brazilian police stations, collected as part of the Third "Week of Visits to Police Stations" (2009) and international research that seeks to engage citizens, as potential users, to evaluate the way police stations deal with the public and the transparency of the services they offer. We seek to relate theoretical definitions of solidarity and justice to particular perceptions of citizenship that can be inferred from the evaluations that were carried out. We thereby structure the following article into three sections, including introduction and conclusion. The first section explains the "Week of Visits to Police Stations" in its different dimensions. The second contextualizes the concepts through which we plan to analyze Brazilian Civil Police actions, that is, civil citizenship and its deficits. The third section discusses how individuals represent the practices they observe in police stations and questions the extent to which these representations converge with the concept of "citizenship deficit" introduced in the previous section. Finally, we present some notes on how the quality of public services provided through police stations can help us understand how in Brazil it is hard to make ideals of justice and solidarity compatible, from a universal perspective. Our results indicate that the attention police stations provide is inadequate and therefore does not mesh with the "principles of justice and solidarity" that give shape to the notion of citizenship itself.

KEYWORDS: Citizenship; Justice; Solidarity; Civil Police; Quality of Police Services. 
São Paulo em Perspectiva, São Paulo, v. 18, n. 1, p. 60-65. Disponível em: http:// www.scielo.br/pdf/spp/v18n1/22227.pdf. Acesso em: 15.maio.2012.

2009. Mapeamento das conexões teóricas e metodológicas da produção brasileira em torno dos temas da violência e da segurança pública e as suas relações com as politicas públicas da área adotadas nas duas últimas décadas (1990-2000). São Paulo: Fundação de Amparo à Pesquisa de São Paulo. Disponível em: http://www.pm.es.gov.br/download/ pesquisa.pdf. Acesso em: 15.maio.2012.

LYRA FILHO, R. 2012. O direito achado na rua. Grupo de estudos "Diálogos Lyrianos". Brasília: UNB. Disponível em: http://odireitoachado narua.blogspot.com.br/. Acesso em: 15.maio. 2012.

MARSHALL, T. H. 1967. Cidadania, classe social e status. Rio de Janeiro: J. Zahar.

MISSE, M. 1999. Malandros, marginais e vagabundos: a acumulação social da violência no Rio de Janeiro. Tese (Doutorado em Sociologia). Instituto Universitário de Pesquisas do Rio de Janeiro.

2010. Crime, sujeito e sujeição criminal: aspectos de uma contribuição analítica sobre a categoria "bandido". Lua Nova, São Paulo, n. 79, p. 15-38. Disponível em: http:// www.scielo.br/pdf/ln/n79/a03n79.pdf. Acesso em: 15.maio.2012.

MISSE, M.; VARGAS, J. D.; TRINDADE, A. C.; RATTON, J. L. \& AZEVEDO, R. G. (orgs.). 2010. O inquérito policial no Brasil: uma pesquisa empírica. Rio de Janeiro: Booklink.

PAIXÃ̃, A. L. 1982. A organização policial numa área metropolitana. Dados, Rio de Janeiro, v. 25 , n. 1 , p. $63-85$.
PANDOLFI, D. 1999. Percepção dos direitos e participação social. In:___. (org.). Cidada nia, justiça e violência. Rio de Janeiro: Fundação Getúlio Vargas.

PERES, M. F. T.; CARDIA, N.; MESQUITA NETO, P.; SANTOS, P. C. \& ADORNO, S. 2000. Homicídios, desenvolvimento socioeconômico e violência policial no Município de São Paulo, Brasil. Revista Panamericana de Salud Publica, Washington (D. C.), v. 23, n. 4, p. 268-276. Disponível em: http://www.scielosp.org/pdf/rpsp/v23n4/ v23n4a07.pdf. Acesso em: 15.maio.2012.

PONCIONI, P. 2006. A "feijoada": negociação e violência nas práticas policiais de mediação de conflitos. Praia Vermelha, Rio de Janeiro, n. 14-15, p. 156-185.

REIS, E. 1999. Cidadania: história, teoria e utopia. In: PANDOLFI, D.; CARNEIRO, L. P.; GRYNSZPAN, M. \& CARVALHO, J. M. (orgs.). Cidadania, justiça e violência. Rio de Janeiro: Fundação Getúlio Vargas.

RIBEIRO, L. M. L. \& SILVA, K. A. 2010. Fluxo do sistema de justiça criminal brasileiro: um balanço da literatura. Cadernos de Segurança Pública, Rio de Janeiro, v. 2, n. 1, p. 14-27. Disponível em: http://www.isp.rj.gov.br/revista/download/Rev20100102.pdf. Acesso em: 15.maio.2012.

TAVARES DOS SANTOS, J. V. 2004. Policía y seguridad ciudadana en Brasil. In: SIERRA, G. \& ALVARADO, M. (orgs.). Democracia, gobernanza y desarrollo en el Mercosur. Montevideo: Organização das Nações Unidas para a Educação, a Ciência e a Cultura.

ZACKSESKI, C. 2009. Los modelos de prevención de conflictos y la participación ciudadana en el Distrito Federal. Inter Criminis, Ciudad de México, n. 10, p. 117-148.

\section{OUTRAS FONTES}

ALTUS. 2010. III Semana de Visitas a Delegacias de Polícia no Brasil. Rio de Janeiro: Fundação Konrad Adenauer.

2012. Sítio de internet. Disponível em: http://www.altus.org. Acesso em: 15.maio. 2012.
LAPOP. 2006. Latin American Public Opinion Project. Disponível em: http://www.vanderbilt. edu/lapop/brazil.php. Acesso em: 15.maio. 2012.

ORGANIZAÇÃO PANAMERICANADE SAÚDE. 2012. Indicadores de saúde. Disponível 
em: http://new.paho.org/bra/index.php? option=com_content\&task=blogcategory\&id= 758\&Itemid=347. Acesso em: 15.maio.2012.

PM faz operação para combater cracolândia do Jacarezinho. 2010. Globo.com, 15.maio. Disponível em: http://g1.globo.com/rio-de-janeiro/noticia/2010/05/pm-faz-operacao-paracombater-cracolandia-do-jacarezinho.html. Acesso em: 15.maio.2012.
SENASP. Ministério da Justiça. 2006. Relatório de gestão. Disponível em: http://portal.mj. gov.br/services/DocumentManagement/ FileDownload.EZTSvc.asp? DocumentID= \{ 93 B 477 D A - B B 7 E - 4 D 3 D - 810 F 381D7C676382 $\} \&$ ServiceInstUID $=\{56$ F1F271B23F-4F33-9071-D0A9027C75E4\}. Acesso em: 15.maio.2012. 


\section{ENTRE LA JUSTICE ET LA SOLIDARITÉ : LA CITOYENNETÉ EXERCÉE DANS LA POLICE CIVILE BRÉSILIENNE}

\section{Ludmila Ribeiro, Julita Lemgruber et Klarissa Almeida Silva}

On discute le rôle de la Police Civile dans un contexte démocratique, quand la citoyenneté devrait se trouver pleinement institutionnalisée. Pour cela, seront utilisées des informations (quantitatives et qualificatives), qui font référence à 235 commissariats brésiliens, recueillies dans le contexte de la « Troisième Semaine de Visites aux Comissariats de Police» (2009), une recherche internationale qui a l'objectif de faire les citoyens, des usagers potentiels des services offerts par ces bureaux, évaluer l'accueil au public et la transparence des services offerts par les commissariats de police. L'objectif c'est de lier les définitions théoriques de solidarité et justice à certaines perceptions de citoyenneté qui peuvent être observées à partir des évaluations réalisées. Pour cela, cet article est structuré en trois sections, en plus de l'introduction et de la conclusion; la première en présente la «Semaine de Visites aux Commissariats de Police» dans ses différentes dimensions. La deuxième section remet dans leur contexte les concepts à partir desquels on a l'intention d'analyser l'action de la Police Civile brésilienne, c'est à dire, la citoyenneté civile et son déficit. Et enfin, la troisième section reproduit les représentations des individus autour des pratiques observées dans les commissariats de police, et problématise la mesure dans laquelle ces pratiques se concilient ou pas avec la catégorie conceptuelle nommée « déficit de citoyenneté », construite dans la section précédente. Enfin, quelques observations sont présentées sur comment la qualité de l'accueil offert par les commissariats de police peut aider à la compréhension de la difficulté existante par rapport à la compatibilité au Brésil, des idéaux de justice et solidarité, à partir d'une perspective universelle. Les résultats indiquent que l'accueil offert par ces bureaux de police est inapproprié et, par conséquent, incapable de se concilier avec les «principes de justice et solidarité » qui structurent l'idée de citoyenneté elle même.

MOTS-CLÉS: citoyenneté; justice; solidarité ; Police Civile; qualité du service policier. 